\title{
TECHNOLOGICAL KNOWLEDGE SPACES AND THE RESILIENCE OF EUROPEAN REGIONS
}

\author{
Silvia Rocchetta ${ }^{1}$ \\ Dublin City University Business School \\ Dublin City University Glasnevin Avenue, D09, Dublin, Ireland \\ silvia.rocchetta@dcu.ie
}

\author{
Andrea Mina ${ }^{2}$ \\ Scuola Superiore Sant'Anna \& EMbeDS, Institute of Economics \\ Piazza Martiri della Libertà, 33, 56127 Pisa, Italy; \\ Centre for Business Research, University of Cambridge, \\ Trumpington Street, Cambridge, CB2 1AG, UK \\ andrea.mina@santannapisa.it \\ Dieter F. Kogler \\ Spatial Dynamics Lab, University College Dublin \\ D04 V1W8, Belfield, Dublin, Ireland \\ dieter.kogler@ucd.ie
}

\section{Changjun Lee}

Department of Media \& Social Informatics, Hanyang University, Ansan, South Korea

changjunlee@hanyang.ac.kr

\footnotetext{
${ }^{1}$ Silvia Rocchetta, Dieter Kogler and Changjun Lee would like to acknowledge funding from the European Research Council under the European Union's Horizon 2020 research and innovation programme (grant agreement No 715631, “TechEvo").

${ }^{2}$ Andrea Mina acknowledges support by the Italian Ministry of Education, University and Research (PRIN2017, project 201799ZJSN: "Technological change, industry evolution and employment dynamics").
} 


\begin{abstract}
Regional knowledge spaces are heterogeneous, and the structure of these knowledge spaces can play a significant role in shaping regional economic performances during economic downturns. This paper explores the relationship between a region's technological profile and its resilience to exogenous shocks. To identify the determinants of regional economic resilience, we perform panel analyses of EU 15 NUTS II level data covering the years before and after the 2008 financial crisis. The most significant results are that, beyond pure diversification effects, regions endowed with technologically coherent capabilities adapted better in times of economic downturn, and that resilience is influenced by a region's capacity to generate new growth paths. These findings deepen our understanding of the evolution of regional economies and have relevant implications for the design of appropriate regional development policy instruments.
\end{abstract}

JEL codes: O30, R11, O33.

Keywords: Resilience, Resistence, Innovation, Technological capabilities, Diversification, Financial crisis, Regional growth. 


\section{Introduction}

Since the outbreak of the Great Recession, the concept of resilience has been increasingly used in the literature to explain the differential performance of regions during the 2008 financial crisis (i.a. Fingleton et al., 2012; Sedita et al., 2017; Bristow and Healy, 2015; Faggian et al., 2018). From a theoretical viewpoint this interest in resilience stems from the need to understand the causes and effects of major discontinuities in the uneven process of regional growth and from the need to better conceptualise the evolution of complex economic systems (Crespo et al., 2013; Boschma, 2015; Martin and Sunley, 2015). From a policy perspective, the question of what might make a region more resilient to crises also has general relevance for the design of regional policy interventions. In the search for empirical evidence, some contributions focus on the sub-national level in order to explore the significant withincountry variation in the resilience of regional industrial agglomerations and local labour markets (Sedita et al., 2017; Holm and Østergaard, 2015; Faggian et al., 2018; Nyström, 2018); others take into account country-level effects of the 2008 financial crisis (Crescenzi et al., 2016; Fratesi and Rodríguez-Pose, 2016; Cappelli et al., 2018). The international financial crisis of 2008 had a profound effect on European economies, which has been well documented (Dijkstra et al., 2015; Crescenzi et al., 2016). ${ }^{3}$ However, despite the noticeable acceleration of research efforts on this topic, the reasons why some regions performed better than others during the recession, net of - or in combination with - national macroeconomic factors, are not fully understood. In this paper we treat resilience as the ability of a regional economy to withstand the impact of an exogenous shock, and link it to the knowledge base structure of regional economies (Kogler et al., 2013; 2017).

To begin with, there is broad agreement on the role of technological knowledge in processes of economic growth (Fagerberg, 1994; Feldman and Kogler, 2010). Following Jacobs (1969), the economic geography literature has stressed the importance of variety in the composition of regional economic activities, because of its potential to generate positive cross-sectoral externalities due to the cross-fertilization of ideas, which in turn generate opportunities for new growth paths. In this paper we are specifically interested in the role that different technological compositions and resulting diversification patterns may have had in shaping the ability of regional economies to withstand macroeconomic shocks. More

\footnotetext{
${ }^{3}$ For a comparative firm-level analysis of geographical (core-periphery) differences in employment performance in the Eurozone, see Mina and Santoleri (2021).
} 
specifically, the Great Recession determined a crisis that like every cyclical downturn generated short run fluctuations in employment trends. Several economists (see for example Pianta et al. 2000 for a discussion of this issue) indicated that investments in technological knowledge play a key role in shaping the economies' ability to improve employment performances during a crisis. Therefore, technological capabilities are a fundamental aspect of economic competitiveness, and the way in which they interact with a shock can provide key indications on the evolution regional economies. This aspect of resilience has not been explored at any length in the literature. We focus on the short-term reaction to the crisis and argue that the development of particular configurations of technological capabilities enables the regions to adjust production in the face of market changes and to sustain economic and occupational performance against the crisis.

Firstly, we build on the literature on regional resilience to qualify the theoretical construct under investigation. Secondly, we examine the drivers of resilience specifically focusing on the short-term effect of variety (related and unrelated), coherence, and the renewal of technology portfolios on employment growth. The empirical tests consist of detailed econometric analyses of a panel of European (EU15) NUTS II level data covering the 2004-2011 period. We use employment growth as dependent variable because recessionary shocks have deep effects on regional job markets (Fratesi and Rodriguez-Pose, 2016), and the falls in employment during a crisis tend to be significantly greater than those in GDP (Martin, 2012), with immediate repercussion for welfare. Our results indicate that during the crisis period, regions with a coherent knowledge base are better able to absorb the shock. Against this clear and robust effect, and differently from previous literature, variety (measured as total entropy, related variety and unrelated variety) does not appear to have any significant positive effect. Moreover, the ability of regions to adapt to the crisis positively depends on entry into new fields, which is the clear mark of processes of structural change.

The paper is organised as follows. In section 2 we review the literature on resilience and profile the theoretical line of the paper. In section 3 we present the data and the variables included in the modelling exercise. In section 4 we present the estimation strategy, results and the robustness checks. We discuss our main findings and then conclude in Section 5 with reference to relevant implications for the design of regional development policy. 


\section{Resilience and Regional Technological Structure: Overview and Hypotheses}

Resilience is a multidimensional concept that has been subject to different interpretations (Bristow and Healy, 2015; Modica and Reggiani, 2015; Xiao et al., 2017; Faggian et al., 2018). Recent publications have persuasively argued that there is still much work to do in order to open up the 'black box' of regional resilience, both from a theoretical and an empirical point of view (Bristow and Healy, 2015; Diodato and Weterings, 2014; Faggian et al., 2018; Nyström, 2018).

The concept of resilience has been defined from three perspectives: engineering, ecological and adaptive, as discussed in some detail in Simmie and Martin (2010). The notion of 'engineering resilience' captures the ability of a system to return to its pre-crisis equilibrium. 'Ecological resilience' involves the system's ability to undergo changes during shocks to retain its structure and identity. Finally, 'adaptive resilience' - the concept that has arguably generated most of the traction in the field of economic geography - indicates the capacity of a regional economy to adapt its productive structure in such a way as to maintain acceptable performance levels through a recession (Martin, 2012).

The literature also discusses different aspects of resilience as a theoretical construct (Martin et al., 2016). Adaptive resilience is, indeed, a complex and a multifaceted process, and can be viewed as comprising different dimensions: vulnerability, also referred to as risk of exposure to downturns or crisis ; resistance, defined as the region's ability to absorb the negative effect of the shock; then, the capacity of the system to reorient its productive structure as an adaptive mechanism against the shock (i.e. qualitative structural change); and finally the ability of the system to recover over time and reach pre-shock performance level. From an empirical viewpoint, it is very difficult to disentangle from one another all these dimensions. Vulnerability might only become apparent at the same time at which the effect of the shock is observed, and the economic system can also simultaneously display resistance and reorientation. Recovery can instead be the effect of resilience, or the longer-term effect of the ability to react to a crisis. In this paper we follow Crescenzi at al.'s approach (2016) and focus on the short-run effects of the 2008 financial crisis on the labour market as a function of the structural characteristics of regional economies.

Recent contribution in economic geography and regional economics have proposed several conjectures that might explain the drivers of regional resilience. Some authors (Fratesi and Rodríguez-Pose 2016; Crescenzi et al., 2016: Cappelli et al., 2019) highlight the 
importance of national macroeconomic factors such as the presence of sheltered economies, healthy account surpluses and human capital in producing uneven growth performances.

Other authors focus more sharply on region-specific factors that increase resilience, such as diversified industrial structures and entrepreneurial orientations (Sedita et al., 2017, Holm and Østergaard, 2015; Faggian et al., 2018; Nyström, 2018); intermediate levels of urbanisation and proximity to cities (Dijkstra et al., 2015); high skill levels and advanced occupational profiles of the workforce (Diodato and Weterings, 2014; Nyström, 2018). Balland et al. (2015) highlight the role of technological capabilities in shaping the resilience of urban economies. Following this line of inquiry several studies note that the composition of a regional technological knowledge base plays a key role in shaping the regional economy's ability to withstand macroeconomic shocks (Crespo et al., 2013; Boschma, 2015; Rocchetta and Mina, 2019). Do particular configurations of the region's technological knowledge foster resilience?

The relationship between innovation and employment over the business cycles is a complex one and has long been a topical issue in economic theory. Since the seminal study of Schumpeter's (1939) 'Business Cycles', the literature on innovation and employment during recessionary shocks approached this issue from several viewpoints, with a revival of interest in the 1970s and 1980s. In his book 'Stalemate in Technology' (1979), Gerhard Mensch proposed what is called the "depression trigger hypothesis": that is, radical innovations tend to be clustered during major economic depressions when firms are more active in the search of technological opportunities to overcome the deterioration of profit rates. The depression trigger hypothesis was, however, criticized by Freeman, Clark and Soete (1982), who argued instead that innovation activities are reduced considerably in long-wave depressions.

With reference to this debate, we build on the evolutionary economic geography literature (Boschma and Martin, 2010; Kogler, 2017a) and elaborate on the concept of variety extensively employed in this research stream to characterise the technological profiles of regions (Rigby and Essletzbichler, 2005; Boschma and Iammarino, 2009; Castaldi et al., 2015). Variety has been used to explore, both theoretically and empirically, the mechanisms through which spillovers occurring between different sectors foster regional economic growth. This notion, derived from Jacob's work (1969), captures the fact that regions with a diversified knowledge structure allow for ideas to be recombined substantially more often than in specialized areas, thus spurring cross-fertilization of knowledge among co-localized agents and entities, and subsequently leading to increased opportunities to innovate. Several 
empirical studies show that variety has a positive effect on regional employment performances (Frenken et al., 2007; McCann, 2013).

Regional variety, via a process that is akin to corporate diversification, can be considered as a portfolio strategy to protect a region from sudden disturbances. For this reason, as argued by Boschma (2015), variety should play a positive effect on regional resilience (i.e. performance against a shock) in the same way in which it favours growth outside recessionary phases on of the business cycle. Regions diversified in more types of economies activities - i.e. products, markets or technologies - may be less likely to experience decline due to idiosyncratic shocks, in line with the arguments proposed by Martin (2012), Sedita et al. (2017), Balland et al. (2015) and Xiao et al. (2017). These studies, which are however limited to single countries or single sectors, stress that variety, by promoting the systems' adaptive capacity (Grabher and Stark,1997), may prevent regions from being locked into declining activities. With specific reference to technologies, it can be argued that regions that have invested in a broader knowledge portfolio have a potentially larger number of opportunities to recombine knowledge. This should lead to a higher probability that regions can identify productive uses of knowledge during a crisis. We therefore propose that:

Hypothesis 1: The degree of regional technological variety has a positive effect on resilience.

Recent findings in the evolutionary economic geography literature (Tanner, 2016; Kogler et al., 2017) contend that regional performance not only depends on the variety in the stock of knowledge present in a region, but also on its precise composition in a qualitative sense. The rationale is that knowledge exchange is easier when it takes place among entities with a common frame of reference (Nooteboom, 2000).

Porter (2003) highlights that externalities stemming from clustered resources, such as technologies, skills, knowledge and acquired inputs, are fundamental for regional growth. This implies that different forms of complementarities or cognitive proximities are very important in defining the opportunities for knowledge recombination (Neffke et al., 2011; Caragliu and Nijkamp, 2015) and for improving the regions' innovative performances (Castaldi et al., 2015). Different forms of cognitive proximity should therefore have a positive effect on regional employment growth, as confirmed by the review of the literature presented and discussed by Content and Frenken (2016). This means that a region characterised by a portfolio of complementary technologies will experience higher 
employment growth rates than a region specialised in sectors or technologies that do not complement each other (Frenken et al., 2007; Kogler et al., 2013). Following Nesta and Saviotti (2005), we define regional coherence as the extent of integration among different knowledge components that make up a regional knowledge base.

Cognitive proximity between the different segments of a specific regional technological portfolio, and the industrial skills associated with the them, are particularly relevant during sector-specific shocks (Neffke and Henning, 2013; Diodato and Weterings, 2014). This is arguably due to the fact that the recombination of coherent components tends to be associated with lower costs and lower levels of uncertainty in learning processes (Fleming, 2001; Fleming and Sorenson, 2001) and this may be especially important during periods of greater financial constraints.

Recent studies (Sedita et al., 2017; Holm and Østergaard, 2015; Rocchetta and Mina, 2019) on Italy, the Danish ICT sector, and the UK, respectively, suggest that during the Great Recession the regional economies' ability to create employment was stronger when their technological structure exhibited a higher degree of coherence. However, it is not clear to what extent these findings are generalizable to an international and cross-sectoral comparative setting, and whether this suggestive but localised evidence holds when we take into account simultaneously the macro level of analysis and all sectors. A focus on NUTS2 regions does not make it possible to provide as fine-grained a resolution as one could obtain from qualitative case-studies, but it can provide much-needed robust and systematic evidence. We argue that the mechanism through which technological coherence favours the performance of regions against a shock is the learning process that make the region able to adjust its productive means around its technological capabilities as opposed to far away from its existing frontier, so that it may efficiently address the specific market challenges posed by the recession. Market demand is likely not only to fall but also to change quite dramatically during a crisis. If the region accumulates technological learning in coherent knowledge spaces, it is more likely to quickly adapt to the new market conditions by varying its offer to suit emergent constraints. This pattern of exploration fosters incremental learning about productive solutions that can dampen the labour market shock as they may not require radically new investments compared to periods when innovators pursue more radical, risky and costly innovation activities (Dosi, 1982). These adjustments in the proximity of the existing frontier do not imply significant processes of reskilling but rather more limited shifts in capability sets. Increased coherence implies that the set of skills required to apply technological knowledge to production is more focused arguably around core sources of 
competitive advantage in local innovation systems. It is also plausible that in the short term, more coherent technological capabilities are associated with greater efficiency in the extraction of productive gains, and more concentration on fewer key assets in comparison with less coherent, and maybe more entropic, exploration activities that would require more disruptive workers reallocation processes. Thus, in times of crisis and against downward shifts in demand or access to credit, the kind of adjustment that is more likely to translate into positive employment outcomes consists mainly of small incremental changes and more focused capability sets, driving innovation processes in the proximity of the existing frontier. This leads us to formulate the following hypothesis:

Hypothesis 2: The degree of technological coherence in a region's technology portfolio has a positive effect on resilience.

Regions evolve through a process of creative destruction where existing products and processes are continuously replaced by newer and more efficient ones (Schumpeter, 1939; Essletzbichler and Rigby, 2005) and new growth paths branch out from existing ones (Garnsey and Heffernan, 2005). This is especially true during economic downturns. This particular aspect of the economic evolution of regions has not been addressed on a large scale and with systematic quantitative data in the resilience literature, despite the great importance that has been attributed to Schumpeterian dynamics of structural change in generating competitive advantage. The creation and accumulation of knowledge are processes that codetermine the capacity of a regional economy to evolve along technological cycles (Kogler, 2017b). Thus, open economic systems continuously undergo endogenously driven change through processes of technological renewal, even if some of these processes are much quicker than others (Metcalfe, 1998).

Martin and Sunley (2006) highlight that the ability of regions to be resilient against shocks does not only depend on their technological structure, but also on their ability to rejuvenate their knowledge bases during a crisis. Regions that branch in new area of technological specialisation during a downturn are able to gain competitive advantage in the market relative to neighbouring regions. The use of newer technologies may lead to increased competiveness and this can translate in a more dynamical job market. Creating new areas of technological specialisation help regions to attract new human capital and this might help regional knowledge space to evolve in new directions. We conjecture that the capacity of regions to enter new domains of technological knowledge helps its reaction to shocks such as financial crises, and mitigates the negative effects on the job market associated with a 
recession. Therefore, as an important complement to the question we have asked about the variety and coherence of regional technology portfolios, we want to test the hypothesis that:

Hypothesis 3: Technological renewal has a positive effect on resilience.

\section{Data and Variables}

\section{Dataset}

The dataset employed and analysed in this study combines information on employment and the industrial composition of NUTS II regions in the EU15 countries with information on patent records. The data sources are the European Regional Database (ERD), EUROSTAT and the European Patent Office (EPO) PATSTAT database. ERD is a service provided by Cambridge Econometrics that contains information on regional employment, level of output and population. Data on workers' education levels were extracted from EUROSTAT regional statistics. We consider patent applications submitted to the EPO by inventors residing ${ }^{4}$ in one of the EU15 NUTS II regions at the time a new product or process was developed. Patent documents contain detailed information about the technical features of their content and thus are categorised into one or more technology classes. For the purpose of the present analysis these are grouped into 8 top-level technological classes and 121 subclasses according to the Cooperative Patent Classification (CPC) system.

The econometric analysis that follows utilises data on 212 EU15 countries' NUTS II regions observed over the 2004-2011 period. ${ }^{5}$ The final dataset is a balanced panel of 1,696 observations, with data merged on the basis of NUTS II regional codes, annually.

\section{Variables and Measures}

\section{Dependent Variable}

In our empirical analyses the dependent variable is the degree of resilience displayed by the EU15 NUTS II regions during the Great Recession that started in 2008. In the literature there is no universally accepted measure of resilience. Several scholars persuasively argue that evaluating differential employment effects is a very efficient empirical strategy to assess the regional economies' abilities to face exogenous shocks (Simmie and Martin, 2010;

\footnotetext{
${ }^{4}$ In the PATSTAT database, patent applications are counted according to the year in which they are filed, and they are assigned to a country/region/province/city on the basis of the inventor's place of residence, using fractional counting if there are multiple inventors for a single patent.

${ }^{5}$ If we run the econometric estimations excluding the year 2011 from the sample, results do not change.
} 
Fingleton, 2012; Bristow and Healy, 2015; Holm and Østergaard, 2015; Fratesi and Rodriguez-Pose, 2016). Variation in employment is the most appropriate measure not only because this can be more adversely affected by a crisis relative to Gross Domestic Product (GDP) or Gross Value Added (GVA), but also because changes in employment reflect the social impact of the crisis much better than other output proxies (Martin et al., 2012). The Great Recession of 2008, led to a fall in final demand that generated dramatic fluctuations in job markets. Fratesi and Rodriguez Pose (2016) stress that in analysing the effects of the crisis employment is also a better measure than unemployment because it captures the differential abilities of regions to be resilient without being affected by changes in labour market participation implied by unemployment measures. In relation to Martin et al.'s resilience framework (2016), the choice of this outcome variable means that the dimension of resilience better captured in this study is the capacity of regions to absorb the negative effect of the shock via short-term adjustments.

Due to the non-stationarity of our employment (level) series, and because we are comparing the performances of regions of very different size, we employ as dependent variable the yearly employment growth rate $\left(\mathrm{gEmp}_{\mathrm{k}, \mathrm{t}}\right)$ in each NUTS II $k$ at time t. The variable is calculated over the period 2004-2011 as a log differential between the regional employment

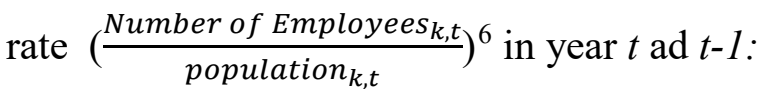

$$
g \text { Emp }_{k t}=\log \left(\text { Employmentrate }_{k, t}\right)-\log \left(\text { Employmentrate }_{k, t-1}\right)
$$

\section{Independent Variables}

In the theory section of the paper we highlighted that technological variety has a positive effect on the capacity of regional economies to be resilient to exogenous shocks. To test our first hypothesis, we include in our econometric estimation three indicators of variety: Regional Entropy, Unrelated and Related Variety. We compute Regional Entropy following the method introduced by Theil (1967). The information entropy index is extensively employed in the literature (Attaran, 1986; Frenken et al., 2007; Boschma and Iammarino, 2009) to evaluate the distribution of different economic activities across firms, industries or regions. In our research we use this variable as a proxy of the degree of patent diversification within a region. To calculate regional entropy for each EU15 NUTS II region we exploit the

\footnotetext{
${ }^{6}$ According to Eurostat the employment rate is the percentage of employed persons in relation to the comparable total population (number of people employed in the region/population of the region) https://ec.europa.eu/eurostat/statisticexplained/index.php?title=Glossary:Employment rate.
} 
information contained in EPO patent application documents about the three-digit CPC technology codes. Entropy is obtained by summing up Unrelated and Related Variety. The latter captures the average degree of patent variety within the subsets and is measured at a lower level of aggregation (3-digit technology code)). Unrelated variety, instead, captures the degree of patent diversification between the higher-order sections (1-digit technology codes).

We can distinguish between the effects of unrelated and related regional diversification on regional resilience because all the patent subclasses $E_{i}(i=1, \ldots, n)$ can be grouped into a sets of events $S_{1}, \ldots \ldots, S_{j}$ in such a way that each patent class falls exclusively within a unique higher-order section $S_{j}$ where $\mathrm{j}=1, \ldots, \mathrm{J}$. Each of the 121 patent classes contained in the dataset can be aggregated into one of the 8 technological sections of the CPC classification. The probability of patent $E_{i}$ is in $S_{j}$ is obtained by summation:

$$
P_{j}=\sum_{i \in S_{j}} p_{i}
$$

Regional Entropy is obtained by summing patent variety between higher-order patent sections (UV) and within lower order patent classes (RV) as follow ${ }^{7}$ :

$$
\text { Entropy }_{j}=U V+R V
$$

Unrelated Variety (UV) - or between-group entropy - is calculated among higherorder sections as follow:

$$
U V=\sum_{i \in S_{j}}^{J} P_{j} \log _{2}\left(\frac{1}{P_{j}}\right)
$$

Related Variety $(\mathrm{RV})$ - the within-groups entropy - is obtained instead as follow:

$$
R V=\sum_{j=1}^{J} P_{j} H_{J}
$$

Where

$$
H_{J}=\sum_{i \in S_{j}} \frac{p_{i}}{P_{j}} \log _{2}\left(\frac{1}{\frac{p_{i}}{P_{j}}}\right)
$$

\footnotetext{
${ }^{7}$ The main disadvantage of calculating Related and Unrelated variety following Theil (1967)'s method is that their values depend entirely on the structure of the Cooperative Patent Classification system. Essentially, this measure implies relatedness based on prior experiences, such as similarities in technological characteristics, while there's no implicit proof if this structure is relevant in practice. Therefore, this measure, does not allow one to capture the whole range of possibilities by which technologies could be related (Boschma et al., 2012).
} 
To test our second hypothesis, we include in our empirical estimation the Regional Technological Coherence index (C). This measure captures the average degree of cognitive proximity across the technologies that compose the regional knowledge base (Nesta and Saviotti, 2005 and 2006).

We employ EPO patent application documents to compute Regional Coherence (C). Following Teece et al. (1994) we calculate the Coherence Index $\left(\tau_{i j}\right)$ to measure the average degree of cognitive proximity across the patent classes that comprise the technological base of NUTS II regions. Our sample includes 212 NUTS II regions each patenting in the period 2004-2011 in some of the 127 technological sections defined by the CPC system. If a NUTS II region $k$ is producing knowledge in technological section then $i G_{i k}=1$, otherwise $G_{i k}=$ 0 . Thus, the number of regions patenting in section $i$ is equal to $K_{i}=\sum_{k} G_{i k}$. Accordingly, the number of regions jointly active in technology $i$ and $j: O_{i j}=\sum_{k} G_{i k} G_{j k}$. Applying the latter to all possible pairs of technological sections it is possible to compute a square (127 X 127) symmetrical matrix $\Omega$, in which the generic cell $O_{i j}$ is the observed number of regions that are jointly patenting in section $i$ and $j$. To identify cases in which pairs of patent classes are appearing more frequently than randomly would suggest we compare the observed value of $O_{i j}$ with the value that would be expected under the hypothesis that technological diversification is random $\mu_{i j}$ as follow:

$$
\tau_{i j}=\frac{O_{i j}-\mu_{i j}}{\sigma_{i j}}
$$

where $\mu_{i j}$ is the media of the counterfactual random sample $X_{i j}$,

$$
\mu_{i j}=E\left(X_{i j}\right)=\frac{K_{i} K_{J}}{K}
$$

$\sigma_{i j}^{2}$ is its variance, and

$$
\sigma_{i j}^{2}=\mu_{i j}\left(1-\frac{K_{i}}{K}\right)\left(\frac{K-K_{J}}{K-1}\right)
$$

where $\mathrm{K}$ is the number of NUTS II regions contained in our database.

Using the degree of technological relatedness within technologies that compose the utilized database one can proceed calculating the Weighted Average Relatedness $W A R_{j k t}$ of technology $j$ with respect to all other $m$ technologies present within the region $k$ at time $t$.

$$
W A R_{j k t}=\frac{\sum_{m \neq j} \tau_{j m} P_{m k t}}{\sum_{m \neq j} P_{m k t}}
$$


$W A R_{j k t}$ is defined as the degree to which technology $j$ is related to all other technologies $m \neq j$ within the region $k$ (at time $t$ ), weighted by the number of patent $P_{m k t}$ of technology $m$ in the specific NUTS II region at time t. Finally, the Regional Technological Coherence $(\mathrm{C})$ of region $k$ at time $t$ is defined as the weighted average of the $W A R_{j k t}$ :

$$
C_{k t}=\sum_{J} W A R_{j i t} \frac{P_{j i t}}{\sum_{j} P_{j i t}}
$$

where $\sum_{j} P_{j k t}$ is the total number of patents within the region k (NUTS II).

This allows us to qualify a particular type of technological learning, i.e. learning that takes place within closer proximity to the regional frontier, which some, but not all regions, may have pursued prior and during the crisis. We use patent applications as manifested outcomes of learning processes that give the region the capacity to adapt its productive processes to the new market conditions dictated by the recession. ${ }^{8}$

The variable Entry is included in the econometric exercise to analyse how regional technological specializations evolve throughout the financial crisis. This index is calculated by exploiting the information in EPO patent applications documents where the data have been regionalised according to the inventor's NUTS II residency at the time of invention. In particular, following the previous literature (Malerba and Montobbio, 2003; Boschma et al., 2012; Kogler et al., 2017), Entry is computed by examining region $k$ 's acquisition of a new technological specialisation in the patent class $j$ at time $t$ which that region did not have at time $t-1$.

$$
\operatorname{Entry}_{k t}=\sum_{j=1}^{J} N e w_{-} R T A_{j k t}
$$

where:

$$
N e w_{-} R T A_{j k t}=1 \text { if } R T A_{j k t}>1 \text { and } 0<R T A_{j k t-1}<1
$$

We measure specialisation by employing a Revealed Technological Advantage indicator (RTA) following Ballassa (1965). This is a binary variable that takes the value 1 when a region has a greater share of patents in technology class $j$ than the reference region (in our case EU15 as a whole), and the value 0 otherwise.

\footnotetext{
${ }^{8}$ If such data existed, one could use R\&D expenditures by micro-technology areas at the finest level of disaggregation. However, not only these data do not exist, but the available (undifferentiated) R\&D series at the NUTS2 level are highly incomplete in our large sample of countries, and cannot be used in our econometric analyses.
} 


\section{Control variables}

We include controls for other regional characteristics. Population is used to control for the demographic size of regions. The share of employees who have a tertiary level of education (Education) for each NUTS II region (i.e. the number of people between 30-34 with a tertiary degree), is included in order to measure regional absorptive capacity (Cohen and Levinthal,1990). It is expected that a larger share of a well-educated workforce positively influences regional resilience because it is better equipped to facilitate the generation of new knowledge, as well as the short and medium-term adaptation to new economic scenarios compared to a scenario that features a less-educated workforce (OECD, 2011).

The regions propensity to produce new knowledge is captured by the variable Patents, which is constructed as the yearly stock of patents weighted by population. The literature suggests that the regional propensity to innovate plays a fundamental role in shaping resilience (among others: Fingleton, 2012; Martin, 2012). The share of employees in the service sector (Serv_Emp) should be considered to control for the region's specialisation in service activities. We expect this variable to be positively associated to resilience, since manufacturing sectors were hit especially hard during the Great Recession. The regional economies' size and their degree of wealth is captured by the variable GDP per capita.

Finally, we include the dummy variable Crisis, first to evaluate the effect of the crisis period on employment, and second to assess how the target variables (variety, coherence and technological renewal) mitigate the effect of the financial crisis. The variable takes the value of 0 until and including the year 2008 and 1 from 2009 onwards. The European job market indeed started to be affected by the Great Recession in $2009^{9}$ (Figure 1).

\section{>>>INSERT FIGURE 1 ABOUT HERE $<<<$}

\section{Descriptive Statistics}

Descriptive statistics and the correlation matrix of dependent and explanatory variables are reported respectively in Table 1 and Table 2 . The correlation matrix shows that the variables that are significantly correlated are Entropy (Entropy), Related Variety (RV) and Unrelated Variety (UV). For this reason, we compute Entropy as the sum of the variables

\footnotetext{
${ }^{9}$ We also analysed employment trends for every country in our sample and defined the dummy crisis for each country according to the year in which its job market started to be affected by the Great Recession. The results of our estimations do not overall change as Ireland was the only country whose job market was immediately (i.e. in 2008) affected by the financial crisis.
} 
RV and UV. Hence, those variables whose correlations exceeded 0.7 were not included in the same regression.

\section{>> >INSERT TABLE 1 ABOUT HERE $<<<$}

\section{>>>INSERT TABLE 2 ABOUT HERE $<<<$}

To gain a first insight into the inter and intra-regional differences in term of resilience we examine the geographical distribution of our dependent variable before and after the Great Recession across the 212 NUTS II EU15 regions. In Figure 2, we map the distribution of average employment growth before and after the crisis started in 2008. By comparing these two maps we can infer that the evolution of regional economies is not only uneven within the same country, but that inter-regional differences became sharper in times the recession hit these regional economies. There are certainly more regions that exhibited negative growth at the time of crisis compared to the time before. Moreover, during the crisis resilience seems to be concentrated in space. The majority of resilient regions are, indeed, located in the core of Europe. The peripheries instead are hit hardest by the Great Recession. ${ }^{10}$

\section{>>>INSERT FIGURE 2 ABOUT HERE $<<<$}

\section{Econometric Analysis and Findings}

When developing suitable empirical analyses, one needs to consider that regional resilience is susceptible to both regional and country-level factors. Several scholars, as noted by Fratesi and Rodríguez-Pose (2016), highlight that nation-specific institutional and political factors play a fundamental role in shaping regional abilities to adapt to the recession. Therefore, we apply a multilevel modelling (MLM) approach that consists of both random

\footnotetext{
${ }^{10} \mathrm{We}$ ran an extensive set of diagnostic analyses on our dependent and main independent variables. With specific reference to technological coherence, in order to reassure the reader that less technologically-advanced regions are not by default more coherent because they have fewer or no patents, we report in the Appendix maps that capture the geographical distribution of coherence (Fig I). While there is no clear pattern for coherence, peripheral regions tend to show less, rather than more coherence relative to core regions, and on average coherence seems to increase in the post-crisis period (see Figure II and III in the appendix) It is of course possible to find cases where coherence increases because of diminuished patenting activities during the crisis. What we are going to investigate in the multivariate analyses is the effect of coherence on employment, conditional on patents and other regional characteristics.In Figure II and III of the appendix we provide additional descriptive insights on this point.
} 
and fixed effects. Multilevel models are well-suited for the treatment of this type of hierarchical data as they enable the decomposing of residual components at each level. In this specific case a two-level model makes it possible to estimate and decompose the total random variation of the regional and country level components. Thus, the residual variance is partitioned into a between-regions component (the variance of the country-level residuals) and a within-countries component (the variance of the regional-level residuals). Compared to other approaches such as cluster-adjusted ordinary least squares, MLM treat the units of analysis as independent observations; CSE techniques would instead treat the random variation as a simple 'disturbance' and by ignoring the multilevel structures of the data, they would underestimate standard errors of the coefficients of higher-level explanatory variables, leading to an overstatement of statistical significance.

The empirical analysis of the determinants of resilience is implemented by adopting a stepwise model. First, we design a model that aims to explain regional employment growth (Equation 1). Secondly, to study the drivers of resilience we interact our key hypothesised determinants with the dummy variable for the crisis period (defined as 0 until and including the year 2008, and 1 afterwards (Equation 2). While the first model captures the effects of employment growth, observation of the interaction effects will constitute the test on the determinants of resilience (i.e. effects conditional on the economic shock).

We use for both estimations random-intercept models with level-one (regional level) and level-two (national level) covariates:

$$
\begin{aligned}
& \text { gEmp }_{i j t}=\beta_{0}+\beta_{2} \text { Entropy }_{i j t-1}+\beta_{3} C_{i j t-1}+\beta_{4} \text { Entry }_{i j t-1}+\beta_{5} \text { Controls }_{i j t-1} \\
& +\beta_{6} \text { rrisis }_{i j t}+u_{i(J) t}+v_{i j t} \\
& \text { gEmp }_{i j t}=\beta_{0}+\beta_{2} \text { Entropy }_{i j t-1}+\beta_{3} C_{i j t-1}+\beta_{4} \text { Entry }_{i j t-1}+\beta_{5} \text { Controls }_{i j t-1}
\end{aligned}
$$

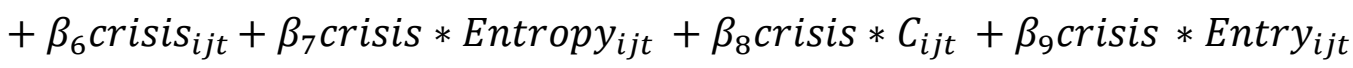

$$
\begin{aligned}
& +u_{i(j) t}+v_{i j t}
\end{aligned}
$$

(Model 2)

where the $i$ represents the Countries and $j$ the regions within each country. All explanatory variables are lagged by one period to mitigate reverse causality problems ${ }^{11}$.

\footnotetext{
${ }^{11}$ Note that in this paper we do not want to investigate whether recessionary shocks may have any permanent effect on the growth ceiling of regions in a steady-state equilibrium framework (see Fingleton et al. (2012) for a discussion of this). This is an interesting avenue for further research, which may require the use of a different econometric framework (i.e. a vector autoregressive model)-The aim of this paper is to understand if different
} 
Table 3 reports the results of the estimations that alternatively include Entropy (Column 1 and Column 4), RV (Column 2 and Column 5) and UV (Column 3 and Column $6)$.

\section{>> >INSERT TABLE 3 ABOUT HERE $<<<$}

The results of the baseline estimation (from Column 1 to 3 ) show that all measures of variety (Entropy, RV and UV) appear to have no effects on employment growth. Regional Technological Coherence (C) and Entry have instead a positive and significant coefficient in all estimations. This evidence suggests that a regional economy's ability to create employment is stronger when its technological structure exhibits a higher degree of coherence and entry into new knowledge domains. Following our conjectures, the model yields positive and significant coefficients for the variables GDP and education, indicating that regions with higher levels of income and with a better educated workforce tend to experience higher employment growth. It is also worth noting that the variable Serv_Emp, which captures the share of workers employed in the service sector, shows positive and significant coefficients.

The results also display negative and significant coefficients in all the different specifications of the model for both, the population and the crisis variable.

The second model (Equation 2) aims to evaluate the determinants of regional resilience. Contrary to our first Hypothesis (Hp 1), the results of the interacted model in Table 3 (column 4 to 6) indicates that technological variety per se (Entropy) and Unrelated Variety (UV) negatively affect regional resilience. Related variety on the other hand appears not to contribute significantly to resilience.

Conversely, hypotheses 2 and 3 are clearly confirmed by the results. As reported in Table 3 (from Column 4 to 6) the coefficients of $\mathrm{C}$ and Entry are positive and highly significant in all estimations. These results validate the idea that the sources of regional resilience are to be found in the degree technological coherence of the regional economy and in regions' ability to branch out in new areas of technological specialisation during the downturn. As we have already noted, analyses conducted at the NUTS2 level cannot uncover the finer details of the process of employment creation (microdata and/or qualitative studies are better suited to this task), but our evidence indicates a clear positive role for specific 
learning investments, captured by the structure of patent applications, which take place within the region and are therefore to some extent 'sticky' to their location because of the tacit (human) component of technological knowledge.

Other things being equal, coherent knowledge bases are conduits of superior performances during recessionary phases of the business cycle. ${ }^{12}$ This effect can be explained by the fact that during periods of demand and resource constraints, building on, and 'bridging across', existing technological specialisations is a better growth path than searching away from the technological frontier of the region: if the economic agents active in the region explore the knowledge space closer to their existing capabilities, and favour more coherent learning activities, they can more efficiently address the market challenges posed by the recession.

Technological renewal also has a positive effect on resilience. ${ }^{13}$ It is important to stress that controlling for the regions' innovation capacity levels makes it possible to disentangle the effect of coherence in quite different contexts: it is theoretically possible that a coherent, but traditional or inward-looking, knowledge base might not foster, but rather hamper growth. This is not what we find. Moreover, consistently with this view, technological renewal exerts a separate and additional effect on resilience.

Contrary to previous literature (Martin, 2012; Sedita et al., 2017; Balland et al., 2015; and Xiao et al., 2017), the results highlight that variety is negatively associated with resilience. It is possible that that this is due to the use in previous studies of measures of related variety based on the hierarchical structure of official industry/technology classifications (NACE/CPC). The weakness of this approach is that it assumes that cognitive similarity only exists within the same group of the industry classification scheme, while failing to capture the entire range of possibilities through which industries could be related to each other (Bishop and Gripaios, 2010; Firgo and Mayerhofer, 2017). Using these measures, it is also difficult to jointly test the effect of variety and other measures of relatedness on regional performance within a single unified framework. This can be accomplished by

\footnotetext{
${ }^{12}$ Coefficients in the interacted model (Table 3) reveals that one unit change in Coherence leads to respectively $0.706 \%, 0.576 \%$ and $0.603 \%$ increase in the employment growth rate during the crisis. However, one of the weakness of these indexes is that is difficult to quantify their impact on the real economy.

${ }^{13}$ Its coefficients in the interacted model (Table 3) indicate that if a region acquires a Revealed Technological Advantage in one more technology leads to respectively $0.636 \%, 0.622 \%$ and $0.60 \%$ increase in employment growth rate during the crisis.
} 
calculating measures based on co-occurrence analyses, as done in Teece et al. (1994); Hidalgo et al. (2007), Neffke (2011) and Kogler (2017).

\section{Robustness checks}

\section{Spatial econometrics specification}

Figure 2 highlight that during the crisis employment growth is much more concentrated in space than in the pre-crisis period. This leads us to investigates if the observed variation of our dependent variable is autocorrelated in space due to lack of independence amongst observations (Anselin and Rey, 1991). This may be due to an interaction of variables across spatial units (lag dependence) or to unobserved variables bias (error dependence) spatial autocorrelation.

To detect if the error term and/or the dependent variable are correlated in space we perform Moran's I and Langrage Multiplier (LM) tests (Table I of the appendix). Both Moran's I and LM statistics suggest the possible presence of spatial autocorrelation in both the dependent and the error term.

The most general specification that accounts both for the spatial autoregressive process (i.e. spatial correlation in the dependent variable) and for spatial autocorrelation (i.e. spatial correlation in the residuals) is the SARAR(SAC) model. In formal terms, a generic representation of this model is:

$$
y=\alpha+\lambda W y+\beta X+\rho W u+\varepsilon
$$

where $W$ is the spatial weight matrix constructed as an inverse distance matrix with row standardization (LeSage and Pace 2009).

The results of spatial panel data analyses are reported in Table 4.

$$
\text { >> INSERT TABLE } 4 \text { ABOUT HERE }<<<
$$

They fully confirm the results of our main estimations and indicate that Technological Coherence $(\mathrm{C})$ and Entry are the main drivers of regional resilience.

\section{Fixed Effects}

Möhring, K. (2012) suggests that fixed effect estimations need to accompany the use of multilevel models applied to cross-national analyses. In order to further test the robustness of our results we therefore run the same estimations using fixed effects. The results reported in table 5 validate our approach and previous results. 


\section{$>>>$ INSERT TABLE 5 ABOUT HERE $<<<$}

\section{Alternative measure of resilience}

To further test the robustness of the results derived from the initial modelling exercise, the same multilevel estimations are performed on an alternative measure of resilience, i.e. the compensation of employees (CE) growth rate. The variable is calculated over the period 2004-2011 as a log differential between the salary level (CE) in year $t$ and $t-1$ divided by the amount of population in the region (pop).

$$
g C E_{k t}=\log \left(\frac{C E_{k, t}}{\operatorname{pop}_{k, t}}\right)-\log \left(\frac{C E_{k, t-1}}{\operatorname{pop}_{k, t-1}}\right)
$$

Compensation of employees is a statistical item used in national accounts, balance of payments statistics and sometimes in corporate accounts as well. It refers to the total gross (pre-tax) wages paid by employers to employees for work done in an accounting period. Several papers in the recent relevant literature employ wage as a measure of resilience (Pendall et al., 2010; Doran and Fingleton, 2016). We argue that is an appropriate alternative measure of resilience because similar to employment it reflects the social impact of the crisis much better than other output proxies like Gross Domestic Product or Gross Value Added.

The results of both the baseline and interacted models that use $g C E$ as dependent variable are reported in Table 6 . They are fully consistent with the main set of estimations.

\section{$>>$ INSERT TABLE 6 ABOUT HERE $<<<$}

\section{Additional robustness checks}

It is possible that regions with better external connections in the production of new technological knowledge have better opportunities to adapt to the shock. As a further test of robustness, we constructed and included in our estimations a proxy (NLKnow) for the share of the new knowledge (number of patents) jointly produced with non-local inventors (inventors which have their residency address outside the region). Table II in the appendix shows the results of estimations inclusive of with the new proxy. The main findings clearly hold. Interestingly, the coefficients for the share of patents with non-local inventors are negative and significant in all estimations, indicating that, contrary to expectations, during the crisis it may have been more difficult to recombine both cognitively and geographically distant knowledge. 


\section{Conclusions}

This study explores the factors affecting the resilience of EU15 NUTS II regional economies during the Great Recession. We began our contribution by reflecting on the unevenness of European regions' labour market performances during the 2008 financial crisis and we set out to explore what aspects of a regional economy are associated with resilience during the economic crisis We conjectured that a fundamental reason has to reside in the heterogeneity of the regional knowledge spaces structures.

Our panel analyses on EU15 NUTS II regions highlight that regions endowed by a coherent technological knowledge base are better able to resist an economic shock. The evidence suggests that this ability is also influenced by a region's capacity to generate new areas of technological specialisation during the downturn.

More specifically our work highlights that during the crisis period employment growth is associated with technological coherence whereas variety has a negative effect. In the regional growth literature variety is usually indicated as a driver of growth. Variety is useful to quantify the breadth of technological capabilities, but does not provide any indication about the degree of cognitive proximity between the knowledge components that make up the regional knowledge base. This result implies that the technological profile (i.e. the structure and evolution) of regions react in very different ways to the macroeconomic context and the business cycle. During economic downturns technological coherence play a key role in fostering employment growth. Higher level of cognitive proximity between knowledge inputs can favour learning in more focused domains especially in times of demand uncertainty. This is arguably due to the fact that in the short-term recombining more similar knowledge bases is less risky and more cost-effective against a crisis. Moreover, technological learning in coherent knowledge spaces may allow to identify new productive solutions for changed - and generally more risk-averse - market conditions, which require small incremental changes in the productive skills. Thus, a technological coherent knowledge base allows regions to produce incremental new knowledge or to refocus capabilities around a 'core', in a way that lowers transactions costs, decrease risks and mitigate job market disruption also during a period of work reallocation.

The empirical analyses indicate that, other things being equal, in the short-term resilience is also driven by the ability of the regions to renew their technological capabilities during a shock. Acquiring a new area of technological specialisation relative to neighbouring 
regions means an increase in regional competitive advantage. This is translated in better short-term employment performances.

The study has, of course, limitations. First of all, more needs to be done to unpack the micro-foundations of regional technological structures and economic performances. We do not analyse the specific types of knowledge that come into play during the crisis period, how they are developed and through what kind of investments. Secondly, it would be worth analysing the characteristics of the technologies that are selected out of the regional knowledge space during the crisis period, and also through what mechanisms this might happen. An especially interesting exercise would be to track the yearly distribution and effects of product innovations relative to improvements in production processes. There is no accepted method to identify these two types of innovation in patent records. Advances in data sciences applied to economic geography might soon provide new tools that could make it possible to explore this important aspect of structural change.

Further research could also shed new light on long-term processes of technological renewal over and across different business cycles. To begin with, the collection of additional per year-observations to our panel would help us to test if during the recovery period regional employment growth might be driven by technological diversification rather than coherence. It is in fact possible that while coherence helps economic performance during a crisis, variety might be a driving force behind subsequent spurs of growth. Moreover, case studies could put to further empirical test our quantitative results. While we have measured resilience as an outcome variable and captured its relationship with the structure and changes of the technological capabilities of regions, in-depth qualitative studies could explore the multiple dimensions of resilience as a contextual process. These might include important factors such as local industrial relations and corporate governance practices.

There are of course also broader implications for the study of resilience and these may also be relevant to the new economic crisis that is unfolding after the COVID-19 pandemic. With reference to the Great Recession, the data show that this widened the differences across and within regions in Europe. In this context, finding solutions to maintain satisfactory growth paths in employment and wealth over time, especially in the face of unexpected downturns, has become a key European policy challenge.

Our results indicate that effective regional resilience strategies should be characterised by a careful assessment of the regional knowledge base structure. The identification of technological capabilities is important to devise the most appropriate incentive schemes and to design innovation policies directed towards the creation of new 
knowledge that is coherent with the existing knowledge base. This is consistent with the view that a careful assessment of the structure of extant technological capabilities should accompany the development of smart specialisation policies. These include interventions based on regions' existing capabilities and sources of competitive advantage relative to the frontier at a time when investments in innovation and technological knowledge are without any doubt considered as a fundamental component of recovery policies also during the unfolding COVID-19 crisis. Moreover, the findings of this paper also suggest that policies aiming to foster regional resilience should boost the development of (coherent) innovative activities by investing in research even during downturns. This is fundamental to foster structural technological change that can support employment in - and out of - the negative phases of the business cycle. 


\section{References}

Anselin, L., \& Rey, S. (1991) Properties of tests for spatial dependence in linear regression models. Geographical analysis, 23(2): 112-131.

Attaran, M. (1986) Industrial diversity and economic performance in U.S. areas. The Annals of Regional Science, 20: 44-54.

Balland, P. A., Rigby, D., \& Boschma, R. (2015) The technological resilience of US cities. Cambridge Journal of Regions, Economy and Society, 8(2): 167-184.

Balassa, B. (1965) Trade liberalisation and "revealed" comparative advantage. The Manchester School, 33(2), 99-123.

Boschma, R. (2015) Towards an evolutionary perspective on regional resilience. Regional Studies, 49 (5): 733-751.

Boschma, R. \& Iammarino, S. (2009) Related variety, trade linkages, and regional growth in Italy. Economic Geography, 85: 289-311.

Boschma, R. \& Martin, R., (2010) The Handbook of Evolutionary Economic Geography, Edward Elgar, Cheltenham (UK) and Northampton (MA).

Boschma, R., Minondo, A., \& Navarro, M. (2012). Related variety and regional growth in Spain, Papers in Regional Science, 91(2): 241-256

Bristow, G., \& Healy, A. (2015) Crisis response, choice and resilience: insights from complexity thinking. Cambridge Journal of Regions, Economy and Society, 8(2): 241256.

Caragliu, A., \& Nijkamp, P. (2015) Space and knowledge spillovers in European regions: the impact of different forms of proximity on spatial knowledge diffusion. Journal of Economic Geography, 16(3): 749-774.

Castaldi, C., Frenken, K., \& Los, B. (2015). Related variety, unrelated variety and technological breakthroughs: an analysis of US state-level patenting. Regional Studies, 49(5): 767-781.

Cohen, W. M., \& Levinthal, D. A. (1990) Absorptive capacity: A new perspective on learning and innovation. Administrative Science Quarterly.

Cortinovis, N., \& Van Oort, F. (2015) Variety, economic growth and knowledge intensity of European regions: a spatial panel analysis. The Annals of Regional Science, 55(1): 732.

Crescenzi, R., Luca, D., \& Milio, S. (2016) The geography of the economic crisis in Europe: national macroeconomic conditions, regional structural factors and short-term economic performance. Cambridge Journal of Regions, Economy and Society, 9(1): 13-22.

Crespo, J., Suire, R., \& Vicente, J. (2013) Lock-in or lock-out? How structural properties of knowledge networks affect regional resilience. Journal of Economic Geography, 14(1):199-219.

Dosi, G. (1982) Technological paradigms and technological trajectories: a suggested interpretation of the determinants and directions of technical change. Research policy, 11(3), 147-162.

Dijkstra, L., Garcilazo, E. \& McCann, P. (2015) The effects of the global financial crisis on European regions and cities, Journal of Economic Geography, 15(5): 935-945. 
Diodato, D., \& Weterings, A. B. (2014) The resilience of regional labour markets to economic shocks: Exploring the role of interactions among firms and workers. Journal of Economic Geography, 15(4): 723-742.

Doran, J., \& Fingleton, B. (2016) Employment resilience in Europe and the 2008 economic crisis: Insights from micro-level data. Regional Studies, 50(4):644-656.

Faggian, A., Gemmiti, R., Jaquet, T., \& Santini, I. (2018). Regional economic resilience: the experience of the Italian local labor systems. The Annals of Regional Science, 60(2), 393410.

Fagerberg, J. (1994) Technology and international differences in growth rates. Journal of economic Literature, 32(3): 1147-1175.

Feldman, M. P., \& Kogler, D. F. (2010) Stylized Facts in the Geography of Innovation. In Handbook of the Economics of Innovation (Vol. 1, pp. 381-410). Amsterdam and Oxford, North-Holland/Elsevier.

Fingleton, B., Garretsen, \& H. Martin, R. (2012) Recessionary shocks and regional employment: evidence on the resilience of U.K. regions. Journal of Regional Science, 52(1): 109-133.

Fleming, L. (2001) Recombinant uncertainty in technological search. Management Science, 47(1): 117-132.

Fleming, L., \& Sorenson, O. (2001) Technology as a complex adaptive system: evidence from patent data. Research Policy, 30(7):1019-1039.

Fratesi, U., \& Rodríguez-Pose, A. (2016) The crisis and regional employment in Europe: what role for sheltered economies?. Cambridge Journal of Regions, Economy and Society, 9(1): 33-57.

Frenken, K., Van Oort F.G., \& Verburg, T. (2007) Related variety, unrelated variety and regional economic growth. Regional Studies: 41, 685-697.

Freeman, C., Clark, J., and Soete, L. (1982). Unemployment and technical innovation: a study of long waves and economic development. Pinter, London.

Garnsey, E., \& Heffernan, P. (2005) High-technology clustering through spin-out and attraction: The Cambridge case. Regional Studies, 39(8): 1127-1144.

Grabher, G. \& Stark, D. (1997) Organizing diversity: evolutionary theory, network analysis and postsocialism. Regional Studies, 31: 533-544.

Holm, J., \& Østergaard, C.R. (2015) Regional employment growth, shocks and regional industrial resilience: a quantitative analysis of the Danish ICT sector. Regional Studies, 49:95-112.

Jacobs, J. (1969) The Economy of Cities. New York: Vintage.

Jaimovich, N., \& Siu, H. E. (2012) The trend is the cycle: Job polarization and jobless recoveries (No. w18334). National Bureau of Economic Research.

Kogler, D. F. (Ed.). (2017a). Evolutionary economic geography: Theoretical and empirical progress. London: Routledge.

Kogler, D. F. (2017b) Relatedness as driver of regional diversification: a research agendaa commentary. Regional Studies, 51(3): 365-369. 
Kogler, D. F., Essletzbichler, J., \& Rigby, D. L. (2017) The evolution of specialization in the EU15 knowledge space. Journal of Economic Geography, 17(2): 345-373.

Kogler, D. F., Rigby, D. L., \& Tucker, I. (2013) Mapping knowledge space and technological relatedness in US cities. European Planning Studies,21(9): 1374-1391.

LeSage J \& Pace K (2009) Introduction to spatial econometrics. CRC Press, Boca Raton.

Malerba, F., \& Montobbio, F. (2003) Exploring factors affecting international technological specialization: the role of knowledge flows and the structure of innovative activity. Journal of evolutionary economics,13(4): 411-434.

Martin, R. (2012) Regional economic resilience, hysteresis and recessionary shocks. Journal of Economic Geography, 12: 1-32.

Martin, R., \& Sunley, P. (2015) On the notion of regional economic resilience: conceptualization and explanation. Journal of Economic Geography 15(1), 1-42.

Martin, R., \& Sunley, P. (2006) Path dependence and regional economic evolution. Journal of economic geography, 6(4): 395-437.

Martin, R., Sunley, P., Gardiner, B., \& Tyler, P. (2016) How regions react to recessions: Resilience and the role of economic structure. Regional Studies, 50(4): 561-585.

McCann P. (2013) Modern Urban and Regional Economics. Oxford: Oxford University Press.

McCann, P., \& Ortega-Argilés, R. (2015) Smart specialization, regional growth and applications to European Union cohesion policy. Regional Studies, 49(8): 1291-1302.

Mensch, G. (1979). Stalemate in technology: innovations overcome the depression. Ballinger Pub Co.

Metcalfe, J.S. (1998) Evolutionary economics and creative destruction (Vol. 1). London Psychology Press

Mina, A., \& Santoleri, P. (2021) 'The effect of the Great Recession on the employment growth of young vs. small firms in the Eurozone', Structural Change and Economic Dynamics, 56: 184-194.

Modica, M., \& Reggiani, A. (2015) Spatial economic resilience overview and perspectives. Networks and Spatial Economics,15(2):211-233.

Neffke, F., \& Henning, M. (2013) Skill relatedness and firm diversification. Strategic Management Journal,34(3): 297-316.

Neffke, F., Henning, M., \& Boschma, R. (2011) How do regions diversify over time? Industry relatedness and the development of new growth paths in regions. Economic Geography, 87, 237-265.

Nesta, L., \& Saviotti, P.P. (2005) Coherence of the knowledge base and the firm's innovative performance: evidence from the U.S. pharmaceutical industry. Journal of Industrial Economics, 53(1): 123-142.

Nesta, L., \& Saviotti P.P. (2006) Firm knowledge and market value in biotechnology. Industrial and Corporate Change, 15(4): 625-652.

Nooteboom, B. (2000) Learning and innovation in organizations and economies. Oxford, Oxford University Press.

Nyström, K. (2018) Regional resilience to displacements. Regional Studies, 52(1): 4-22. 
Pendall, R., Foster, K. A., \& Cowell, M. (2010) Resilience and regions: building understanding of the metaphor. Cambridge Journal of Regions, Economy and Society, 3(1): 71-84.

Penrose, E. T. (1959) The theory of the growth ofthe firm. New York: Sharpe.

Porter, M. (2003) The economic performance of regions. Regional studies, 37(6-7): 549578.

Rigby, D. L., \& Essletzbichler, J. (2005) Technological variety, technological change and a geography of production techniques. Journal of Economic Geography, 6(1): 45-70.

Rocchetta, S., \& Mina, A. (2017) Technological Coherence and the Adaptive Resilience of Regional Economies. Papers in Evolutionary Economic Geography, 17.

Rodríguez-Pose, A. (2018) The revenge of the places that don't matter (and what to do about it). Cambridge Journal of Regions, Economy and Society, 11(1): 189-209.

Schumpeter, J. A. (1939) Business cycles (Vol. 1, pp. 161-74). New York: McGraw-Hill.

Sedita S.R., De Noni I., Pilotti L. (2017) "Out of the crisis: an empirical investigation of place-specific determinants of economic resilience”. European Planning Studies, 25(2), 155-180.

Simmie, J., Martin, R. (2010) The economic resilience of regions: towards an evolutionary approach. Cambridge Journal of Regions, Economy and Society, 3(1): 27-43.

Tanner, A. N. (2016) The emergence of new technology-based industries: The case of fuel cells and its technological relatedness to regional knowledge bases. Journal of Economic Geography, 16(3): 611-635.

Teece, D.J., Rumelt, R., Dosi, G., \& Winter, S. (1994) Understanding corporate coherence: theory and evidence. Journal of Economic Behavior and Organisation, 23: 1-30.

Theil, H. (1967) Economics and information theory, Amsterdam: North-Holland

Xiao, J., Boschma, R., \& Andersson, M. (2017) Resilience in the European Union: the effect of the 2008 crisis on the ability of regions in Europe to develop new industrial specializations. Industrial and Corporate Change,27(1): 15-47. 
Figure 1 - Evolution of EU15 Employment 2004-2011

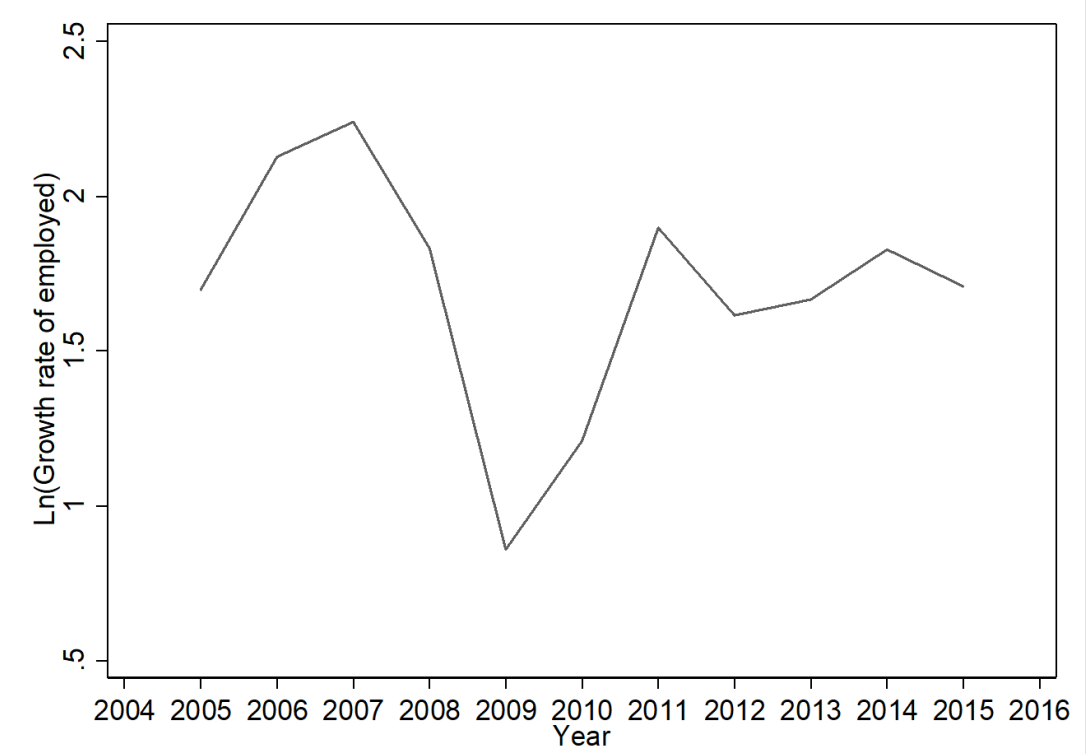

Source: Cambridge Econometrics, own calculations

Figure 2 - Evolution of EU15 NUTS II Employment Growth before and after the Great Recession

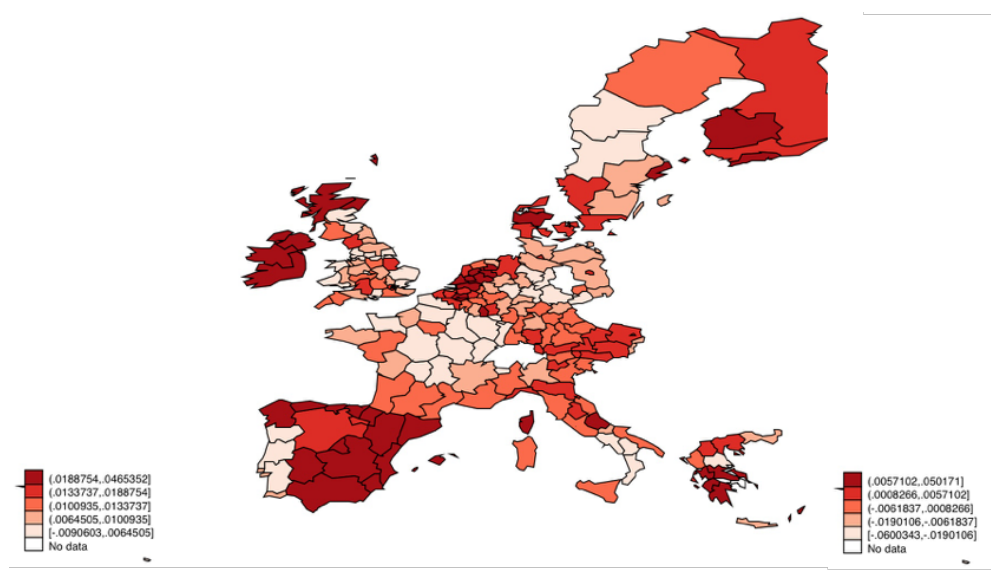

Employment Growth 2004-2008

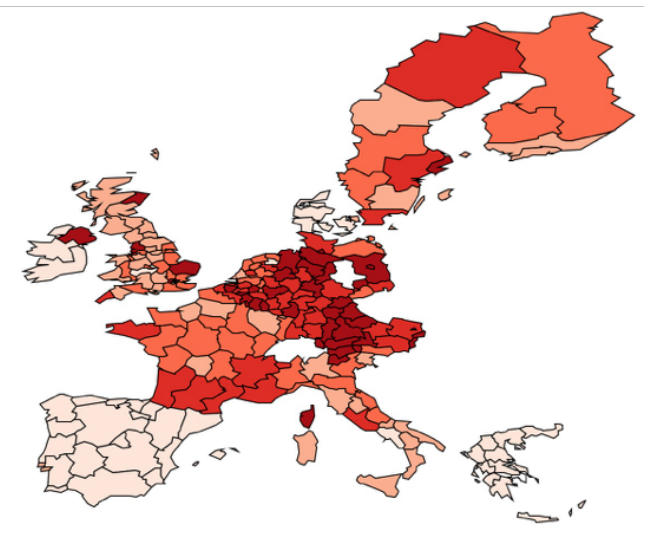

Employment Growth 2009-2011

Source: Cambridge Econometrics, own calculation 
Table 1 - Descriptive statistics

\begin{tabular}{lccccc}
\hline \hline & Obs & Mean & Std. Dev. & Min & Max \\
\hline gEmp & 1477 & 0,00 & 0,21 & $-0,13$ & 0,15 \\
Entropy & 1688 & 4,26 & 1,37 & 0,00 & 5,88 \\
RV & 1688 & 1,76 & 0,80 & 0,00 & 3,02 \\
UV & 1688 & 2,19 & 1,03 & 0,00 & 3,09 \\
C & 1688 & 8,44 & 1,08 & 0,00 & 12,77 \\
Entry & 1687 & 13,35 & 6,09 & 0,00 & 30,00 \\
Education & 1583 & 31,99 & 10,47 & 10,60 & 77,50 \\
Patent & 1649 & 0,17 & 0,19 & 0,00 & 1,13 \\
Serv_Emp & 1688 & 316,41 & 296,55 & 7,80 & 2129,44 \\
Pop & 1696 & 0,599 & 0,791 & 0,033 & 5,00 \\
GDP & 1477 & 0,00 & 0,03 & $-0,15$ & 0,17 \\
Crisis & 1696 & 0,38 & 0,48 & 0,00 & 1,00 \\
\hline \hline
\end{tabular}

Table 2 - Correlation Matrix

\begin{tabular}{|c|c|c|c|c|c|c|c|c|c|c|c|c|}
\hline & gEmp & Entropy & RV & $\mathbf{U V}$ & C & Entry & Edu & Patent & Serv_Emp & Pop & GDP & Crisis \\
\hline gEmp & 1 & & & & & & & & & & & \\
\hline Entropy & 0.0878 & 1 & & & & & & & & & & \\
\hline RV & 0.0996 & 0.9512 & 1 & & & & & & & & & \\
\hline $\mathbf{U V}$ & 0.0599 & 0.9176 & 0.7502 & 1 & & & & & & & & \\
\hline $\mathbf{C}$ & -0.0287 & 0.1341 & 0.1268 & 0.1241 & 1 & & & & & & & \\
\hline Entry & 0.0895 & 0.2110 & 0.2159 & 0.1741 & 0.1543 & 1 & & & & & & \\
\hline Education & -0.0075 & -0.1114 & -0.1395 & -0.0589 & 0.1040 & 0.0600 & 1 & & & & & \\
\hline Patent & 0.1807 & 0.2358 & 0.2779 & 0.1474 & 0.1375 & 0.0203 & 0.0923 & 1 & & & & \\
\hline Serv_Emp & -0.0443 & -0.0160 & -0.0147 & -0.0152 & -0.0647 & -0.0692 & -0.1896 & -0.1112 & 1 & & & \\
\hline Pop & -0.0139 & 0.0409 & 0.0522 & 0.0205 & 0.0396 & 0.1613 & 0.0573 & 0.0907 & -0.2949 & 1 & & \\
\hline GDP & 0.5553 & 0.1126 & 0.1329 & 0.0701 & 0.0093 & 0.0971 & -0.0153 & 0.1886 & -0.0040 & -0.0126 & 1 & \\
\hline Crisis & -0.4921 & 0.0061 & 0.0052 & 0.0064 & -0.0295 & 0.0235 & 0.1531 & 0.0102 & 0.0006 & 0.0077 & -0.3348 & 1 \\
\hline
\end{tabular}


Table 3 - Results of the Multilevel Estimations

\begin{tabular}{|c|c|c|c|c|c|c|}
\hline & $\begin{array}{c}\text { (1) } \\
\text { gEmp }\end{array}$ & $\begin{array}{c}(2) \\
\text { gEmp }\end{array}$ & $\begin{array}{c}\text { (3) } \\
\text { gEmp }\end{array}$ & $\begin{array}{c}(4) \\
\text { gEmp }\end{array}$ & $\begin{array}{c}\text { (5) } \\
\text { gEmp }\end{array}$ & $\begin{array}{c}\text { (6) } \\
\text { gEmp }\end{array}$ \\
\hline Entropy & $\begin{array}{c}0.00119 \\
(0.000721)\end{array}$ & & & $\begin{array}{c}0.00170^{*} \\
(0.000732)\end{array}$ & & \\
\hline $\mathbf{R V}$ & & $\begin{array}{c}0.00117 \\
(0.000751)\end{array}$ & & & $\begin{array}{c}0.00148^{*} \\
(0.000743)\end{array}$ & \\
\hline $\mathbf{U V}$ & & & $\begin{array}{c}0.000801 \\
(0.000935)\end{array}$ & & & $\begin{array}{c}0.00178 \\
(0.000922)\end{array}$ \\
\hline $\mathbf{C}$ & $\begin{array}{c}0.00271^{* * *} \\
(0.000665)\end{array}$ & $\begin{array}{c}0.00271^{* * *} \\
(0.000665)\end{array}$ & $\begin{array}{c}0.00260^{* * *} \\
(0.000740)\end{array}$ & $\begin{array}{c}0.00128^{*} \\
(0.000617)\end{array}$ & $\begin{array}{c}0.00143^{*} \\
(0.000608)\end{array}$ & $\begin{array}{c}0.00117 \\
(0.000704)\end{array}$ \\
\hline Entry & $\begin{array}{l}0.00233 * * \\
(0.000837)\end{array}$ & $\begin{array}{l}0.00234 * * \\
(0.000837)\end{array}$ & $\begin{array}{l}0.00248 * * \\
(0.000877)\end{array}$ & $\begin{array}{l}-0.000582 \\
(0.000834)\end{array}$ & $\begin{array}{l}-0.000532 \\
(0.000835)\end{array}$ & $\begin{array}{l}-0.000137 \\
(0.000910)\end{array}$ \\
\hline Education & $\begin{array}{c}0.00632 * * \\
(0.00194)\end{array}$ & $\begin{array}{c}0.00626 * * \\
(0.00194)\end{array}$ & $\begin{array}{c}0.00546 * * \\
(0.00192)\end{array}$ & $\begin{array}{c}-0.0000723 \\
(0.00176)\end{array}$ & $\begin{array}{l}-0.000220 \\
(0.00176)\end{array}$ & $\begin{array}{l}-0.000462 \\
(0.00181)\end{array}$ \\
\hline Patents & $\begin{array}{l}0.000752 \\
(0.00355)\end{array}$ & $\begin{array}{l}0.000712 \\
(0.00355)\end{array}$ & $\begin{array}{l}-0.00200 \\
(0.00384)\end{array}$ & $\begin{array}{l}-0.00165 \\
(0.00314)\end{array}$ & $\begin{array}{l}-0.00174 \\
(0.00314)\end{array}$ & $\begin{array}{l}-0.00440 \\
(0.00352)\end{array}$ \\
\hline Serv_Emp & $\begin{array}{c}0.0456 * * * \\
(0.0110)\end{array}$ & $\begin{array}{c}0.0456^{* * *} \\
(0.0110)\end{array}$ & $\begin{array}{c}0.0844 * * * \\
(0.0115)\end{array}$ & $\begin{array}{l}0.0312 * * \\
(0.00983)\end{array}$ & $\begin{array}{l}0.0313 * * \\
(0.00985)\end{array}$ & $\begin{array}{c}0.0673 * * * \\
(0.0106)\end{array}$ \\
\hline Pop & $\begin{array}{c}-0.120 * * * \\
(0.0201)\end{array}$ & $\begin{array}{c}-0.119 * * * \\
(0.0201)\end{array}$ & $\begin{array}{c}-0.110^{* * *} \\
(0.0222)\end{array}$ & $\begin{array}{c}-0.159 * * * \\
(0.0181)\end{array}$ & $\begin{array}{c}-0.158 * * * \\
(0.0182)\end{array}$ & $\begin{array}{c}-0.151 * * * \\
(0.0206)\end{array}$ \\
\hline GDP & $\begin{array}{c}0.00225 * * * \\
(0.000538)\end{array}$ & $\begin{array}{c}0.00225 * * * \\
(0.000538)\end{array}$ & $\begin{array}{c}0.00253 * * * \\
(0.000573)\end{array}$ & $\begin{array}{c}0.00363 * * * \\
(0.000491)\end{array}$ & $\begin{array}{c}0.00363 * * * \\
(0.000492)\end{array}$ & $\begin{array}{c}0.00356 * * * \\
(0.000539)\end{array}$ \\
\hline Crisis & $\begin{array}{c}-0.0164 * * * \\
(0.00122)\end{array}$ & $\begin{array}{c}-0.0164 * * * \\
(0.00122)\end{array}$ & $\begin{array}{c}-0.0150 * * * \\
(0.00131)\end{array}$ & $\begin{array}{c}-0.0259 * * * \\
(0.00123)\end{array}$ & $\begin{array}{c}-0.0260 * * * \\
(0.00123)\end{array}$ & $\begin{array}{c}-0.0245^{* * * *} \\
(0.00137)\end{array}$ \\
\hline Entropy*Crisis & & & & $\begin{array}{c}-0.00329 * \\
(0.00154)\end{array}$ & & \\
\hline $\mathbf{R V} *$ Crisis & & & & & $\begin{array}{l}-0.00185 \\
(0.00117)\end{array}$ & \\
\hline $\mathbf{U V} *$ Crisis & & & & & & $\begin{array}{c}-0.00248^{*} \\
(0.00118)\end{array}$ \\
\hline $\mathrm{C} *$ Crisis & & & & $\begin{array}{c}0.00706^{* * * *} \\
(0.00180)\end{array}$ & $\begin{array}{c}0.00576 * * * \\
(0.00156)\end{array}$ & $\begin{array}{c}0.00603 * * * \\
(0.00175)\end{array}$ \\
\hline Entry*Crisis & & & & $\begin{array}{c}0.00636^{* * *} \\
(0.00134)\end{array}$ & $\begin{array}{c}0.00622 * * * \\
(0.00134)\end{array}$ & $\begin{array}{c}0.00607 * * * \\
(0.00144\end{array}$ \\
\hline Constant & $\begin{array}{c}0.0285 * * * \\
(2.93)\end{array}$ & $\begin{array}{l}0.0284 * * * \\
\quad(2.92)\end{array}$ & $\begin{array}{c}0.0518 * * * \\
\quad(4.94)\end{array}$ & $\begin{array}{c}0.0134 \\
(1.55)\end{array}$ & $\begin{array}{c}0.0134 \\
(1.55)\end{array}$ & $\begin{array}{c}0.0349 * * * \\
\quad(3.60)\end{array}$ \\
\hline \multicolumn{7}{|l|}{ Random Effects } \\
\hline $\begin{array}{l}\sigma_{u} \\
\sigma_{v}\end{array}$ & $\begin{array}{c}3.18 \mathrm{e}-12 * * * \\
(1.87 \mathrm{e}-11) \\
0.0143 * * * \\
(0.000313)\end{array}$ & $\begin{array}{c}3.19 \mathrm{e}-12 * * * \\
(1.86 \mathrm{e}-11) \\
0.0143 * * * \\
(0.000313)\end{array}$ & $\begin{array}{c}6.26 \mathrm{e}-12 * * * \\
(3.93 \mathrm{e}-11) \\
0.0160 * * * \\
(0.00033)\end{array}$ & $\begin{array}{c}2.76 \mathrm{e}-12 * * * \\
(1.63 \mathrm{e}-11) \\
0.0126 * * * \\
(0.000277)\end{array}$ & $\begin{array}{c}2.74 \mathrm{e}-12 * * * \\
(1.63 \mathrm{e}-11) \\
0.0126 * * * \\
(0.000277)\end{array}$ & $\begin{array}{r}5.73 \mathrm{e}-12 * * * \\
(3.62 \mathrm{e}-11) \\
0.0147 * * * \\
(0.000303) \\
\end{array}$ \\
\hline Obs & 1158 & 1158 & 1158 & 1158 & 1187 & 1187 \\
\hline N Regions & 212 & 212 & 212 & 212 & 212 & 212 \\
\hline N Countries & 15 & 15 & 15 & 15 & 15 & 15 \\
\hline
\end{tabular}

Estimated intercept and slope coefficients for each regressor with robust standard errors in parentheses. Asterisks denote significance: * $\mathrm{p}<0.05, * * \mathrm{p}<0.01, * * * \mathrm{p}<0.001$. 
Table 4 - Diagnostic tests for spatial autocorrelations

\begin{tabular}{cccc}
\hline Test & Statistic & df & p-value \\
\hline Spatial error: & & & \\
Moran's I & 8,674 & 1 & $0.000^{* * *}$ \\
Lagrange multiplier & 23,489 & 1 & $0.000^{* * *}$ \\
Spatial lag: & & & \\
Lagrange multiplier & 49,977 & 1 & $0.000^{* * *}$ \\
\hline
\end{tabular}


Table 5 - Results of the SPARAR Estimations

\begin{tabular}{|c|c|c|c|c|c|c|}
\hline & $\begin{array}{c}(1) \\
\text { gEmp }\end{array}$ & $\begin{array}{l}(2) \\
\text { gEmp }\end{array}$ & $\begin{array}{c}(3) \\
\text { gEmp }\end{array}$ & $\begin{array}{c}(4) \\
\text { gEmp }\end{array}$ & $\begin{array}{c}\text { (5) } \\
\text { gEmp }\end{array}$ & $\begin{array}{l}\text { (6) } \\
\text { gEmp }\end{array}$ \\
\hline Entropy & $\begin{array}{c}0.000165 \\
(0.000399)\end{array}$ & & & $\begin{array}{l}0.000229 \\
0.000229\end{array}$ & & \\
\hline RV & & $\begin{array}{c}0.000364 \\
(0.000760)\end{array}$ & & & $\begin{array}{c}0.00148 * \\
(0.000743)\end{array}$ & \\
\hline $\mathbf{U V}$ & & & $\begin{array}{c}0.000167 \\
(0.000706)\end{array}$ & & & $\begin{array}{c}0.00178 \\
(0.000922)\end{array}$ \\
\hline $\mathbf{C}$ & $\begin{array}{l}0.00114 * * \\
(0.000389)\end{array}$ & $\begin{array}{l}0.00114 * * \\
(0.000389)\end{array}$ & $\begin{array}{l}0.00114 * * \\
(0.000389)\end{array}$ & $\begin{array}{c}0.000448 \\
(0.000426)\end{array}$ & $\begin{array}{c}0.000448 \\
(0.000426)\end{array}$ & $\begin{array}{c}0.000447 \\
(0.000426)\end{array}$ \\
\hline Entry & $\begin{array}{l}0.0413 * \\
(0.0189)\end{array}$ & $\begin{array}{l}0.0414^{*} \\
(0.0189)\end{array}$ & $\begin{array}{l}0.0412 * \\
(0.0189)\end{array}$ & $\begin{array}{c}0.000196 \\
(0.000121)\end{array}$ & $\begin{array}{c}0.000197 \\
(0.000121)\end{array}$ & $\begin{array}{c}0.000195 \\
(0.000121)\end{array}$ \\
\hline Education & $\begin{array}{c}-0.000138 \\
(0.0000805)\end{array}$ & $\begin{array}{c}-0.000139 \\
(0.0000805)\end{array}$ & $\begin{array}{c}-0.000140 \\
(0.0000805)\end{array}$ & $\begin{array}{c}-0.000139 \\
(0.0000802)\end{array}$ & $\begin{array}{c}-0.000140 \\
(0.0000802)\end{array}$ & $\begin{array}{c}-0.000141 \\
(0.0000802)\end{array}$ \\
\hline Patents & $\begin{array}{l}-0.00410 \\
(0.0161)\end{array}$ & $\begin{array}{l}-0.00411 \\
(0.0161)\end{array}$ & $\begin{array}{l}-0.00412 \\
(0.0161)\end{array}$ & $\begin{array}{l}-0.00721 \\
(0.0160)\end{array}$ & $\begin{array}{r}-0.00722 \\
(0.0160)\end{array}$ & $\begin{array}{l}-0.00714 \\
(0.0160)\end{array}$ \\
\hline Serv_Emp & $\begin{array}{l}0.0413 * \\
(0.0189)\end{array}$ & $\begin{array}{l}0.0414^{*} \\
(0.0189)\end{array}$ & $\begin{array}{l}0.0412 * \\
(0.0189)\end{array}$ & $\begin{array}{c}0.0102 \\
(0.0207)\end{array}$ & $\begin{array}{l}0.00998 \\
(0.0207)\end{array}$ & $\begin{array}{c}0.0103 \\
(0.0207)\end{array}$ \\
\hline Pop & $\begin{array}{c}-0.0000650 * * * \\
(0.0000103)\end{array}$ & $\begin{array}{c}-0.0000650 * * * \\
(0.0000103)\end{array}$ & $\begin{array}{c}-0.0000650 * * * \\
(0.0000103)\end{array}$ & $\begin{array}{c}-0.159 * * * \\
(0.0181)\end{array}$ & $\begin{array}{c}-0.158 * * * \\
(0.0182)\end{array}$ & $\begin{array}{c}-0.151^{* * *} \\
(0.0206)\end{array}$ \\
\hline GDP & $\begin{array}{c}0.0681 * * * \\
(0.0154)\end{array}$ & $\begin{array}{c}0.0681 * * * \\
(0.0154)\end{array}$ & $\begin{array}{c}0.0681 * * * \\
(0.0154)\end{array}$ & $\begin{array}{c}0.0691 * * * \\
(0.0154)\end{array}$ & $\begin{array}{c}0.0689 * * * \\
(0.0154)\end{array}$ & $\begin{array}{c}0.0692 * * * \\
(0.0154)\end{array}$ \\
\hline Crisis & $\begin{array}{l}-0.00864 * \\
(0.00430)\end{array}$ & $\begin{array}{l}-0.00864 * \\
(0.00430)\end{array}$ & $\begin{array}{l}-0.00863 * \\
(0.00430)\end{array}$ & $\begin{array}{l}-0.0193 * * \\
(0.00628)\end{array}$ & $\begin{array}{l}-0.0192 * * \\
(0.00633)\end{array}$ & $\begin{array}{l}-0.0196 * * \\
(0.00633)\end{array}$ \\
\hline Entropy*Crisis & & & & $\begin{array}{l}-0.000454 \\
(0.000522)\end{array}$ & & \\
\hline $\mathbf{R V} *$ Crisis & & & & & $\begin{array}{c}0.000546 \\
(0.000807)\end{array}$ & \\
\hline $\mathbf{U V} *$ Crisis & & & & & & $\begin{array}{c}-0.000737 \\
(0.000958)\end{array}$ \\
\hline C*Crisis & & & & $\begin{array}{l}0.00182 * * \\
(0.000557)\end{array}$ & $\begin{array}{l}0.00181 * * \\
(0.000557)\end{array}$ & $\begin{array}{l}0.00182 * * \\
(0.000559)\end{array}$ \\
\hline Entry*Crisis & & & & $\begin{array}{l}0.000426^{*} \\
(0.000167)\end{array}$ & $\begin{array}{l}0.000421^{*} \\
(0.000167)\end{array}$ & $\begin{array}{l}0.000429^{*} \\
(0.000167)\end{array}$ \\
\hline Log_likehood & 3552.83 & 3552.83 & 3552.83 & 3552.83 & 3552.83 & 3552.83 \\
\hline rho & $\begin{array}{l}0.814 * * * \\
(0.0644)\end{array}$ & $\begin{array}{l}0.814 * * * \\
(0.0644)\end{array}$ & $\begin{array}{l}0.814 * * * \\
(0.0644)\end{array}$ & $\begin{array}{l}0.764 * * * \\
(0.0776)\end{array}$ & $\begin{array}{l}0.764 * * * \\
(0.0776)\end{array}$ & $\begin{array}{l}0.764 * * * \\
(0.0776)\end{array}$ \\
\hline lambda & $\begin{array}{c}0.781 * * * \\
(0.0735)\end{array}$ & $\begin{array}{c}0.781 * * * \\
(0.0735)\end{array}$ & $\begin{array}{c}0.781 * * * \\
(0.0735)\end{array}$ & $\begin{array}{c}0.828 * * * \\
(0.0550) \\
\end{array}$ & $\begin{array}{c}0.828 * * * \\
(0.0550)\end{array}$ & $\begin{array}{c}0.828 * * * \\
(0.0550)\end{array}$ \\
\hline Obs & 1484 & 1484 & 1484 & 1484 & 1484 & 1484 \\
\hline N Regions & 212 & 212 & 212 & 212 & 212 & 212 \\
\hline R-sq & 0.28 & 0.28 & 0.28 & 0.30 & 0.30 & 0.30 \\
\hline
\end{tabular}

Estimated intercept and slope coefficients for each regressor with robust standard errors in parentheses. Asterisks denote significance: * $\mathrm{p}<0.05, * * \mathrm{p}<0.01, * * * \mathrm{p}<0.001$ 
Table 6 - Results of the Multilevel Estimations with an alternative measure of regional resilience

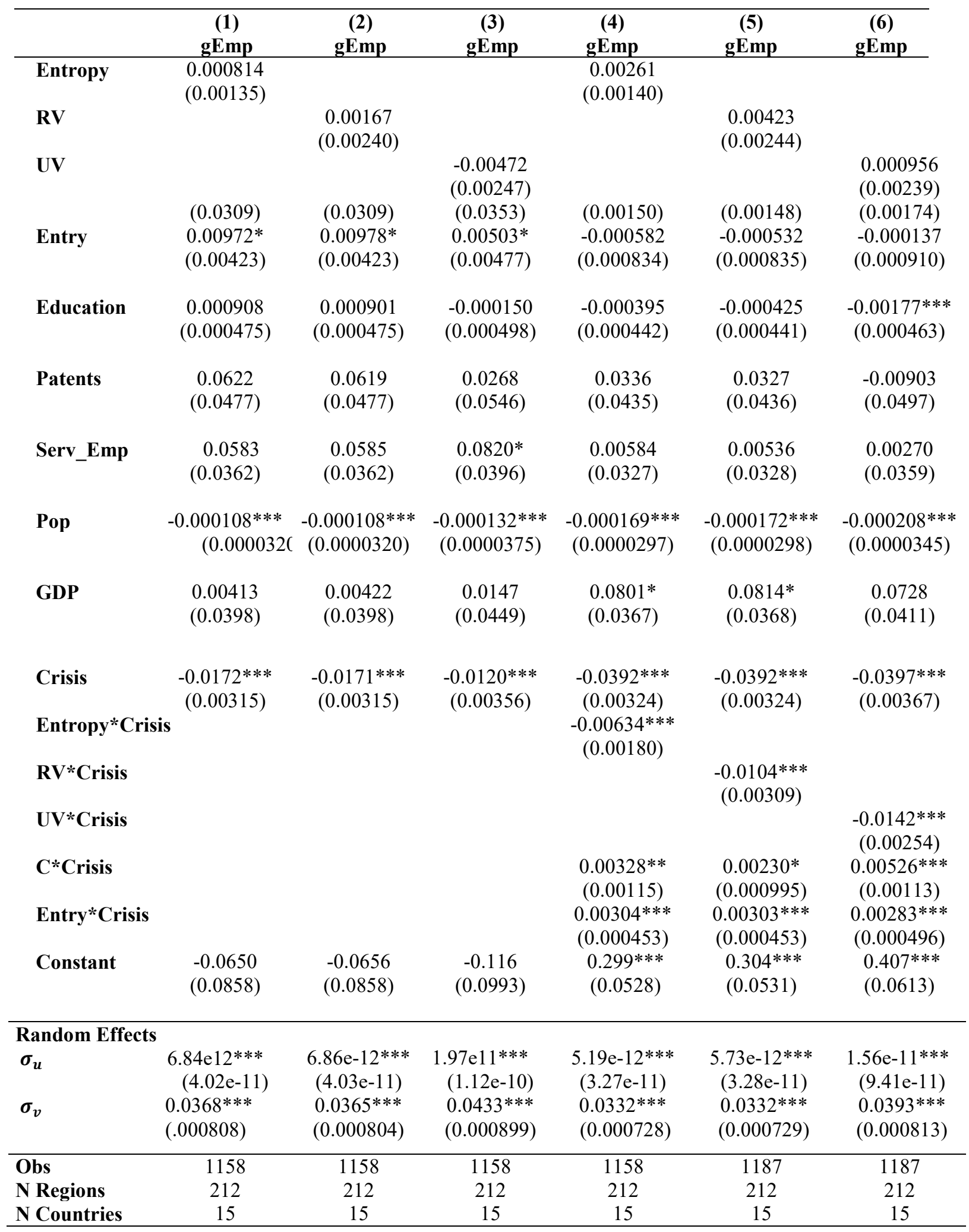

Estimated intercept and slope coefficients for each regressor with robust standard errors in parentheses. Asterisks denote significance: * $\mathrm{p}<0.05, * * \mathrm{p}<0.01, * * * \mathrm{p}<0.001$ 


\section{APPENDIX}

Figure I- EU15 NUTS II Coherence before and after the Great Recession

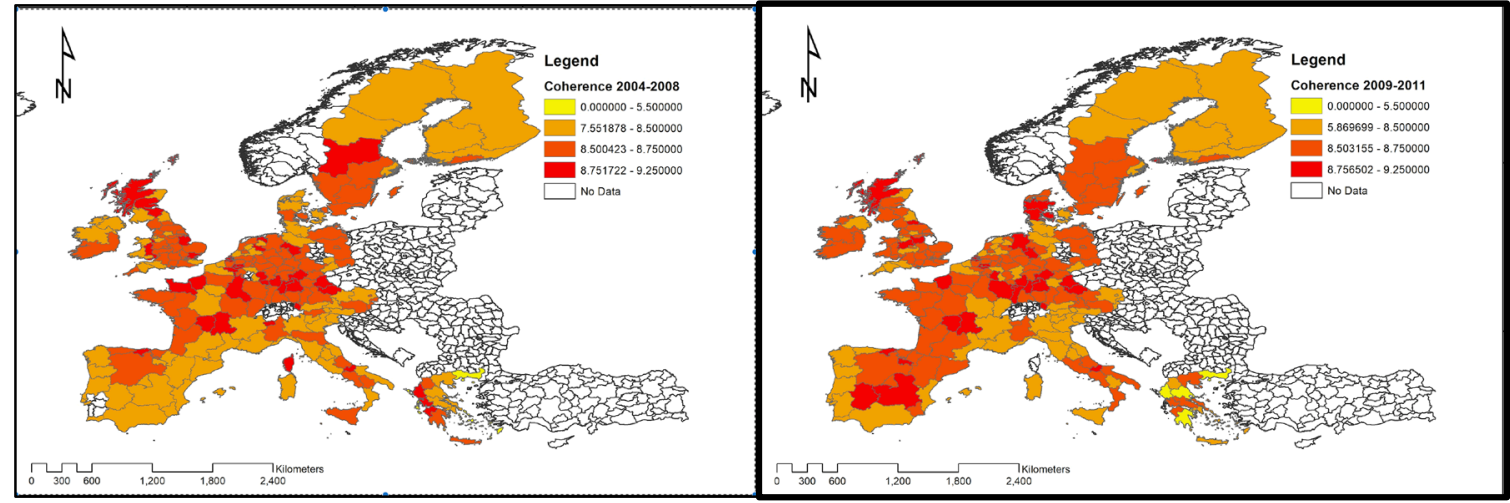

Figure II - Patents, Coherence and employment growth before and during the crisis
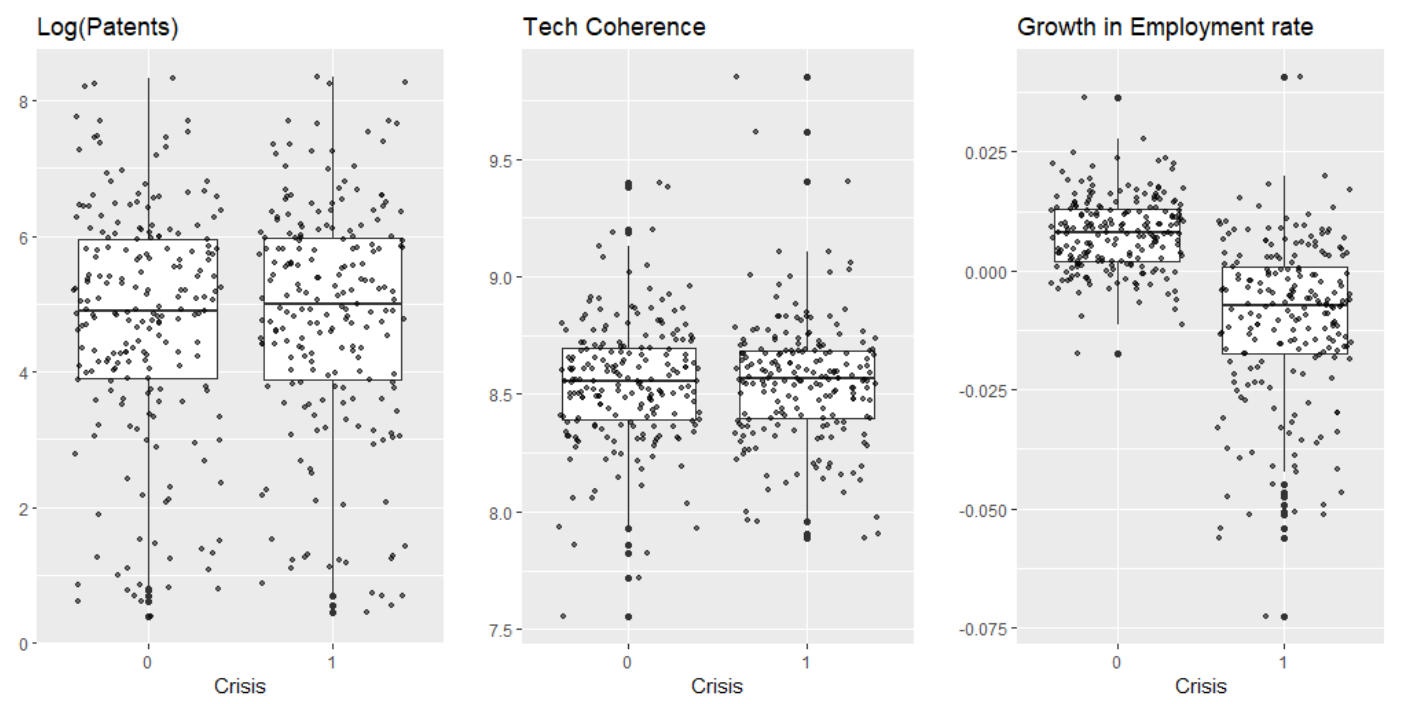

Figure III- Employment performances and coherence conditional on patenting

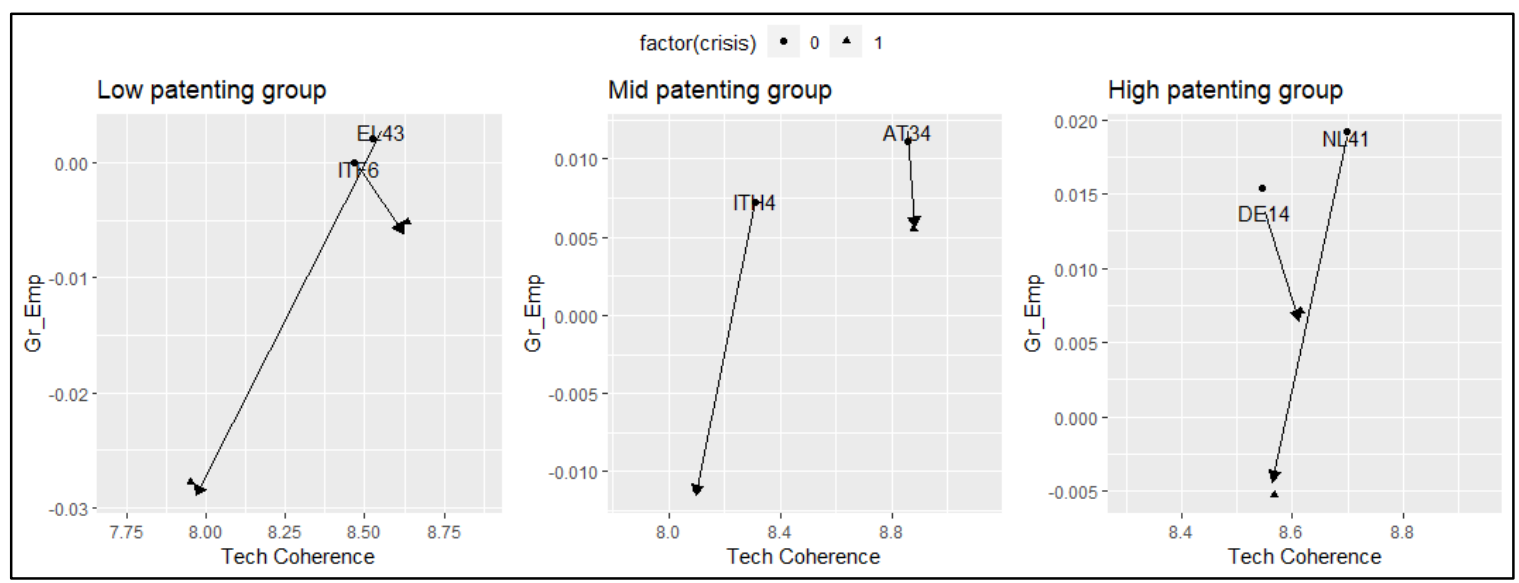

In the figure we have divided the regions into three groups by level of patenting (Low / Mid / High). For the low-patenting group we include Crete (EL43) vs. Calabria (ITF6), for the mid-patenting group Vorarlberg (AT34) vs. Friuli-Venezia Giulia (ITH4), and for the high-patenting group Noord-Brabant (NL41) vs. Tübingen (DE14). The pairs, matched by patenting levels, display different employment patterns during the crisis, and these correspond to changes in technological coherence. The data suggest that in the short term Calabria performed better in term of employment growth during crisis than Crete, despite having the same patenting level, because Calabria raised its coherence. The same happened to Vorarlberg relative to Friuli-Venezia Giulia, and to Tübingen relative to Noord-Brabant. 
Table I - Diagnostic tests for spatial autocorrelations

\begin{tabular}{cccc}
\hline Test & Statistic & df & p-value \\
\hline $\begin{array}{c}\text { Spatial error: } \\
\text { Moran's I }\end{array}$ & 8,674 & 1 & $0.000^{* * * *}$ \\
Lagrange multiplier & 23,489 & 1 & $0.000^{* * *}$ \\
Spatial lag: & & & \\
Lagrange multiplier & 49,977 & 1 & $0.000^{* * *}$ \\
\hline
\end{tabular}


Table II - Results of the estimations with a proxy for the externally generated new knowledge

\begin{tabular}{|c|c|c|c|c|c|c|}
\hline & $\begin{array}{c}(1) \\
\text { gEmp }\end{array}$ & $\begin{array}{c}(2) \\
\text { gEmp }\end{array}$ & $\begin{array}{c}\text { (3) } \\
\text { gEmp }\end{array}$ & $\begin{array}{c}\text { (4) } \\
\text { gEmp }\end{array}$ & $\begin{array}{c}(5) \\
\text { gEmp }\end{array}$ & $\begin{array}{c}\text { (6) } \\
\text { gEmp }\end{array}$ \\
\hline Entropy & $\begin{array}{c}0.000893 \\
(0.000525)\end{array}$ & & & $\begin{array}{c}0.00111 * \\
(0.000534)\end{array}$ & & \\
\hline RV & & $\begin{array}{c}0.00154 \\
(0.000936)\end{array}$ & & & $\begin{array}{c}0.00164 \\
(0.000929)\end{array}$ & \\
\hline $\mathbf{U V}$ & & & $\begin{array}{c}0.000770 \\
(0.000904)\end{array}$ & & & $\begin{array}{c}0.00166 \\
(0.000891)\end{array}$ \\
\hline $\mathbf{C}$ & $\begin{array}{c}0.00282 * * * \\
(0.000661)\end{array}$ & $\begin{array}{c}0.00270 * * * \\
(0.000735)\end{array}$ & $\begin{array}{c}0.00283 * * * \\
(0.000661)\end{array}$ & $\begin{array}{c}0.00112 \\
(0.000616)\end{array}$ & $\begin{array}{c}0.00127 * \\
(0.000606)\end{array}$ & $\begin{array}{c}0.000971 \\
(0.000703)\end{array}$ \\
\hline Entry & $\begin{array}{c}0.000394 * * \\
(0.000138)\end{array}$ & $\begin{array}{c}0.000418 * * \\
(0.000144)\end{array}$ & $\begin{array}{c}0.000397 * * \\
(0.000138)\end{array}$ & $\begin{array}{l}0.0000862 \\
(0.000137)\end{array}$ & $\begin{array}{c}0.0000763 \\
(0.000137)\end{array}$ & $\begin{array}{c}0.0000184 \\
(0.000150)\end{array}$ \\
\hline Education & $\begin{array}{c}0.000582 * * \\
(0.000185)\end{array}$ & $\begin{array}{c}0.000504 * * \\
(0.000184)\end{array}$ & $\begin{array}{c}0.000576 * * \\
(0.000185)\end{array}$ & $\begin{array}{l}0.0000234 \\
(0.000168)\end{array}$ & $\begin{array}{l}0.0000104 \\
(0.000168)\end{array}$ & $\begin{array}{c}0.00000382 \\
(0.000174)\end{array}$ \\
\hline Patents & $\begin{array}{l}0.00413 \\
(0.0187)\end{array}$ & $\begin{array}{c}0.0103 \\
(0.0202)\end{array}$ & $\begin{array}{l}0.00390 \\
(0.0187)\end{array}$ & $\begin{array}{c}0.0141 \\
(0.0166)\end{array}$ & $\begin{array}{c}0.0147 \\
(0.0166)\end{array}$ & $\begin{array}{c}0.0284 \\
(0.0187)\end{array}$ \\
\hline Serv_Emp & $\begin{array}{c}0.0578 * * * \\
(0.0139)\end{array}$ & $\begin{array}{c}0.107 * * * \\
(0.0145)\end{array}$ & $\begin{array}{c}0.0579 * * * \\
(0.0139)\end{array}$ & $\begin{array}{c}0.0397 * * \\
(0.0124)\end{array}$ & $\begin{array}{c}0.0400 * * \\
(0.0124)\end{array}$ & $\begin{array}{c}0.0849 * * * \\
(0.0133)\end{array}$ \\
\hline Pop & $\begin{array}{c}-0.00007 * * * \\
(0.0000125)\end{array}$ & $\begin{array}{c}-0.00006 * * * \\
(0.0000139)\end{array}$ & $\begin{array}{l}-0.00007 * * * \\
(0.0000125)\end{array}$ & $\begin{array}{l}-0.0001 * * * \\
(0.0000117)\end{array}$ & $\begin{array}{c}-0.0001 * * \\
(0.0000117)\end{array}$ & $\begin{array}{l}-0.0001 * * * \\
(0.0000134)\end{array}$ \\
\hline GDP & $\begin{array}{c}0.0634 * * * \\
(0.0153)\end{array}$ & $\begin{array}{c}0.0713 * * * \\
(0.0163)\end{array}$ & $\begin{array}{c}0.0635 * * * \\
(0.0153)\end{array}$ & $\begin{array}{c}0.104 * * * \\
(0.0139)\end{array}$ & $\begin{array}{c}0.103 * * * \\
(0.0139)\end{array}$ & $\begin{array}{c}0.102 * * * \\
(0.0153)\end{array}$ \\
\hline NLKnow & $\begin{array}{c}0.0000260 \\
(0.0000173)\end{array}$ & $\begin{array}{c}0.0000262 \\
(0.0000194)\end{array}$ & $\begin{array}{c}0.0000266 \\
(0.0000173)\end{array}$ & $\begin{array}{c}0.0000162 \\
(0.0000153)\end{array}$ & $\begin{array}{c}0.0000170 \\
(0.0000153)\end{array}$ & $\begin{array}{c}0.0000165 \\
(0.0000178)\end{array}$ \\
\hline Crisis & $\begin{array}{c}-0.0162 * * * \\
(0.00122)\end{array}$ & $\begin{array}{c}-0.0149 * * * \\
(0.00131)\end{array}$ & $\begin{array}{c}-0.0162 * * * \\
(0.00122)\end{array}$ & $\begin{array}{c}-0.0258 * * * \\
(0.00123)\end{array}$ & $\begin{array}{c}-0.0258 * * * \\
(0.00123)\end{array}$ & $\begin{array}{c}-0.0243 * * * \\
(0.00137)\end{array}$ \\
\hline Entropy*crisis & & & & $\begin{array}{c}0.00113 \\
(0.000694)\end{array}$ & & \\
\hline $\mathbf{R V} \mathbf{*}^{*}$ crisis & & & & & $\begin{array}{c}0.00123 \\
(0.00120)\end{array}$ & \\
\hline UV*crisis & & & & & & $\begin{array}{c}0.00183 \\
(0.000951)\end{array}$ \\
\hline C*Crisis & & & & $\begin{array}{c}0.00230 * * * \\
(0.000491)\end{array}$ & $\begin{array}{c}0.00204 * * * \\
(0.000446)\end{array}$ & $\begin{array}{c}0.00211 * * * \\
(0.000512)\end{array}$ \\
\hline Entry*Crisis & & & & $\begin{array}{c}0.00082 * * * \\
(0.000172)\end{array}$ & $\begin{array}{c}0.00080 * * * \\
(0.000172)\end{array}$ & $\begin{array}{c}0.00080 * * * \\
(0.000186)\end{array}$ \\
\hline NLKnow*crisis & & & & $\begin{array}{c}-0.0224 * * \\
(0.00857)\end{array}$ & $\begin{array}{c}-0.0230 * * \\
(0.00862)\end{array}$ & $\begin{array}{c}-0.0211 * \\
(0.00952)\end{array}$ \\
\hline Constant & $\begin{array}{c}0.0782 * * * \\
(0.0221) \\
\end{array}$ & $\begin{array}{c}0.0687 * * \\
(0.0244)\end{array}$ & $\begin{array}{c}0.0789 * * * \\
(0.0221) \\
\end{array}$ & $\begin{array}{c}0.166 * * * \\
(0.0209) \\
\end{array}$ & $\begin{array}{c}0.166^{* * * *} \\
(0.0210) \\
\end{array}$ & $\begin{array}{c}0.155 * * * \\
(0.0239)\end{array}$ \\
\hline \multicolumn{7}{|l|}{ Random Effects } \\
\hline rho & $\begin{array}{c}3.24 \mathrm{e}-12 * * * \\
(1.89 \mathrm{e}-11)\end{array}$ & $\begin{array}{c}6.37 \mathrm{e}-12 * * * \\
(3.98 \mathrm{e}-11)\end{array}$ & $\begin{array}{c}3.24 \mathrm{e}-12 * * * \\
(1.89 \mathrm{e}-11)\end{array}$ & $\begin{array}{c}2.80 \mathrm{e}-12 * * * \\
(1.65 \mathrm{e}-11)\end{array}$ & $\begin{array}{c}2.79 \mathrm{e}-12 * * * \\
(1.64 \mathrm{e}-11)\end{array}$ & $\begin{array}{c}5.84 \mathrm{e}-12 * * * \\
(3.65 \mathrm{e}-11)\end{array}$ \\
\hline lamda & $\begin{array}{l}0.0143 * * * \\
(0.000313) \\
\end{array}$ & $\begin{array}{l}0.0160 * * * \\
(0.000331) \\
\end{array}$ & $\begin{array}{l}0.0143 * * * \\
(0.000313) \\
\end{array}$ & $\begin{array}{l}0.0126 * * * \\
(0.000276) \\
\end{array}$ & $\begin{array}{l}0.0126 * * * \\
(0.000276) \\
\end{array}$ & $\begin{array}{l}0.0146 * * * \\
(0.000303) \\
\end{array}$ \\
\hline Obs & 1158 & 1158 & 1187 & 1158 & 1158 & 1187 \\
\hline N Regions & 212 & 212 & 212 & 212 & 212 & 212 \\
\hline N Countries & 15 & 15 & 15 & 15 & 15 & 15 \\
\hline
\end{tabular}

Estimated intercept and slope coefficients for each regressor with robust standard errors in parentheses. Asterisks denoted significance: $* \mathrm{p}<0.05, * * \mathrm{p}<0.01, * * * \mathrm{p}<0.001$. 